\title{
Behaviour of U-shaped RC walls under quasi-static cyclic diagonal
}

\section{loading}

\section{Raluca Constantin ${ }^{\text {a }}$, Katrin Beyer ${ }^{\text {b }}$}

${ }^{a}$ Earthquake Engineering and Structural Dynamics Laboratory (EESD), School of Architecture, Civil and Environmental Engineering (ENAC), École Polytechnique Fédérale de Lausanne (EPFL), Switzerland.

EPFL ENAC IIC EESD, GC B2 515, Station 18, CH - 1015 Lausanne

Tel: +41216936321

raluca.constantin@epfl.ch

b Earthquake Engineering and Structural Dynamics Laboratory (EESD), School of Architecture, Civil and Environmental Engineering (ENAC), École Polytechnique Fédérale de Lausanne (EPFL), Switzerland.

EPFL ENAC IIC EESD, GC B2 504, Station 18, CH - 1015 Lausanne

Tel: +41216936234

Tel: +41216935706

katrin.beyer@epfl.ch 


\begin{abstract}
This article presents results from the experimental testing of two half-scale $R C U$-shaped walls under quasi-static cyclic bidirectional loading along the diagonal direction of the U-shaped section, which were recently completed at EPFL. The main objective of the article is to emphasise particularities in the behaviour of $U$-shaped walls under diagonal loading and to point out related design and analysis issues. Several phenomena specific to diagonal loading are discussed: (1) strain gradient across the wall width promotes out-of-plane buckling of the boundary elements in the flange ends; (2) plane section analysis does not yield reliable moment capacity estimates for the diagonal loading direction and (3) under diagonal loading the compression depth in the flange end boundary elements is larger than for the other loading directions, exposing unconfined concrete to large compressive strains. These phenomena lead to a reconsideration of the following design and analysis issues for U-shaped walls: (a) the distribution of the vertical reinforcement layout; (b) the use of plane section analysis for estimating the strength capacity of the wall; $(c)$ the confinement length of the boundary elements of the flanges; and $(d)$ the assessment of the out-of-plane stability of flange ends.
\end{abstract}

Keywords: U-shaped wall; Diagonal loading; Quasi-static cyclic test; Axial load ratio; Longitudinal reinforcement layout 


\section{Introduction}

Recent research and design advances on seismic behaviour of reinforced concrete (RC) core walls with open cross-sections were mainly obtained through experimental testing ([1]-[6]). Since core walls provide horizontal strength and stiffness in both horizontal directions, these test programmes were performed under different horizontal load patterns in order to obtain a better understanding of their behaviour. Three of these test programmes ([1], [2] and [5]) focused on U-shaped walls and have shown the complex behaviour such walls exhibit under bidirectional loading. The diagonal loading direction has been identified as a particular critical one as: the displacement capacity is the smallest of all horizontal loading directions [2], the distribution of the shear forces between the different wall sections is complex ([1]-[2]) and the load transfer mechanism from the wall to the foundation unclear.

Aiming to complement the existing knowledge on U-shaped walls, a new test programme on such walls was recently completed at EPFL in Lausanne, Switzerland. The objective of the test programme was to investigate the U-shaped wall behaviour when loaded along the diagonal direction of the U-shaped section. More specifically, the programme focused on identifying failure mechanisms specific to diagonal loading and possible critical design aspects related to these failure modes as well as particular phenomena that could explain the load transfer mechanisms between wall sections and wall and foundation for loading in the diagonal direction.

This article discusses the experimental results of the new test campaign emphasising observed phenomena typical to Ushaped walls under diagonal loading. In more detail, the document shows that: (1) the difference in vertical strains on the inner and outer side of the flange ends promotes out-of-plane buckling failure under diagonal loading; (2) plane sections do not remain plane under diagonal loading and plane section analysis does not lead to reliable moment capacity estimates and (3) the compression depth under diagonal loading with one flange end in compression is significantly larger than in the orthogonal loading cases and can for larger axial load ratios extend along the entire flange, making it difficult to provide effective confinement.

The paper is organized in several sections. The test units, the test setup, the loading history and the instrumentation are presented in Section 2. Section 3 describes the failure mechanisms, the hysteretic behaviour as well as key deformation quantities that highlight the section deformation at the wall base, the out-of-plane bending of the flange end and the shear 
deformations of the wall sections. Section 4 gives a summary of the findings concluding with recommendations for analysis and design.

\section{Test units, setup, instrumentation and loading history}

The test campaign is a continuation of the previous test campaign on U-shaped walls from ETH Zurich [2]. Therefore the overall geometry of the test units is the same and the test setup is very similar as in the previous test campaign. The two test programmes differed only with regard to the reinforcement layouts of the walls, the instrumentation and the loading history. A detailed description of the design of the test setup and of the test units can be found in Beyer et al. [2] and is hence not repeated herein. Therefore the following sections discuss only briefly the geometry of the new test units including reinforcement layouts (Section 2.1), material properties (Section 2.2), test setup and the instrumentation (Section 2.1) as well as the loading history (Section 2.2).

\subsection{Geometry of the tests units}

The two U-shaped walls tested as part of this project were half-scale models of the lower two storeys of a prototype elevator shaft and had the same dimensions as test unit TUB in [2]. Both test units, named TUC (Test Unit C) and TUD (Test Unit D) had identical longitudinal reinforcement layouts (Figure 1) but differed with regard to the applied axial load ratio and shear reinforcement: TUC was subjected to an axial load ratio of 0.06 and TUD to an axial load ratio of 0.15 . The higher axial load ratio was applied to account for the effects of possible increase in axial force due to the shear force transferred by coupling beams. To account for the higher shear force demand of TUD, the shear reinforcement percentage was increased by $\sim 25 \%$ as compared with TUC. To maximise the amount of experimental information collected, it was decided to modify the reinforcement layout of TUB slightly and investigate also the influence of the vertical reinforcement distribution on the behaviour of the two wall flanges. Therefore, for both walls one flange was detailed with vertical reinforcement mainly concentrated in the boundary elements while in the other flange and the web the vertical reinforcement was uniformly distributed along the wall section. The reinforcement layout for the two test units is shown in Table 1. The vertical reinforcement content of the two flanges in the boundary elements and in the unconfined part is given for comparison in Table 1, together with the reinforcement contents of the web and the entire wall. 


\subsection{Material properties}

The material properties of both test units are given in Table 2 and Table 3. The material tests were performed in accordance with the Swiss Norm SIA262/1 [7]. The concrete tensile strength $f_{t}^{\prime}$ was derived from double-punch tests [8]. Concrete properties from material tests are: concrete compressive strength $f_{c}^{\prime}$, concrete elastic modulus $E_{c}$ and the concrete tensile strength $f_{t}^{\prime}$ correspond to properties at the day of testing, except the $f_{c}^{\prime}$ - 28 days strength, which corresponds to the cylinder concrete compressive strength at 28 days.

The yield strength $f_{y}$, the ultimate strength $f_{u}$ and the ultimate strain $\varepsilon_{s u}$ of the reinforcement bars are given in Table 3 and correspond to properties at the day of testing. Additionally, for the D12 bars, the hardening strain is given, which marks the end of the constant strength yield plateau and the beginning of increasing strength strain-hardening zone. With values of $f_{u} / f_{y}$ between 1.18 and 1.26 and values of $\varepsilon_{s u}$ between 6.9 and $9.6 \%$, the D8 and D12 bars belong to "Class C" grade according to Eurocode 8 [9], while the D6 bars belong to "Class B" due to the strain value $\varepsilon_{s u}$ lower than $7.5 \%$.

(a)

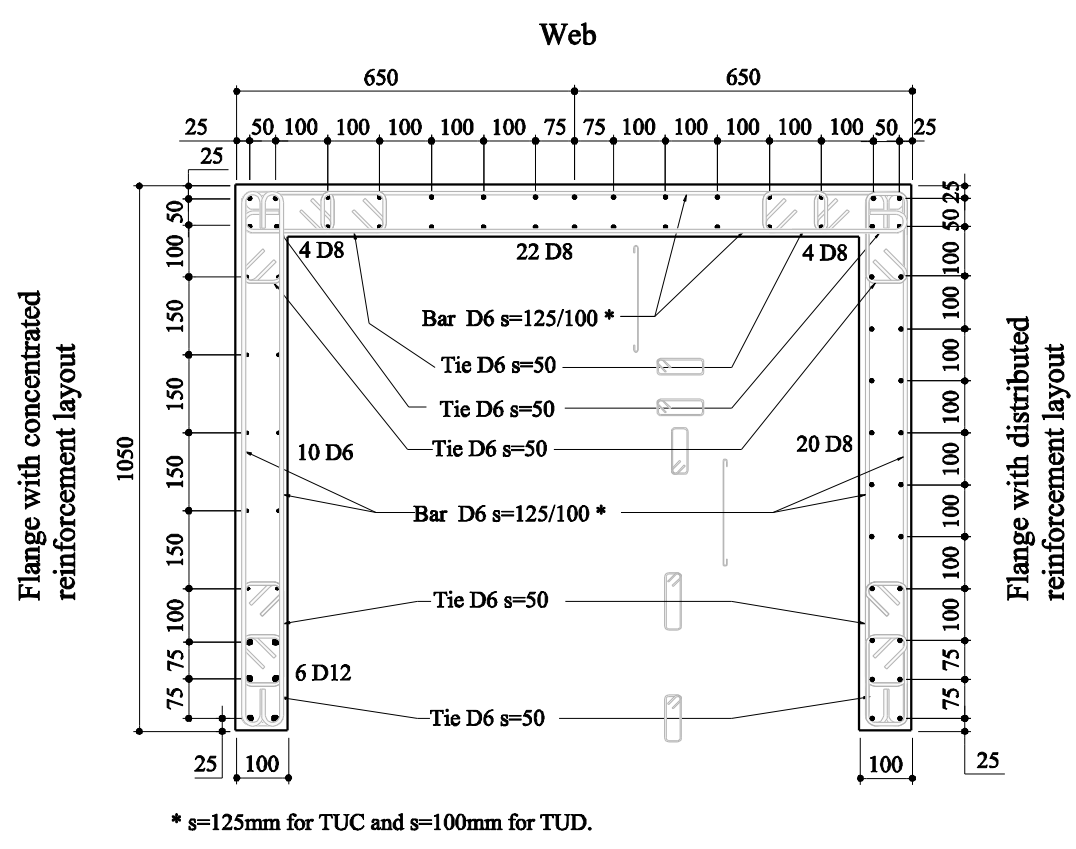

(b)

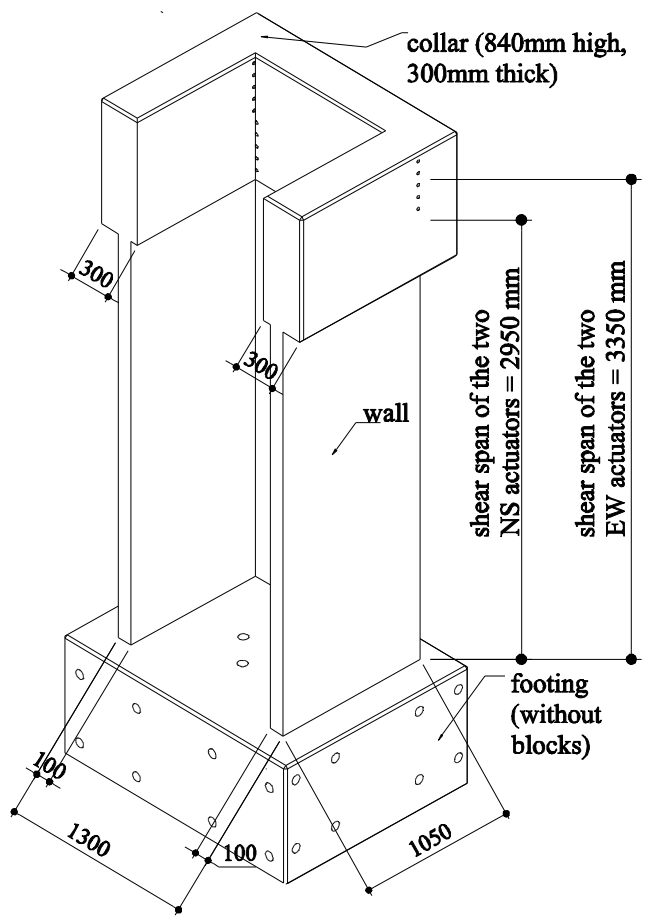

Figure 1 Test units TUC and TUD: cross-section and reinforcement layout (a) and elevation (b) 
Table 1 Vertical reinforcement percentages for TUC and TUD computed for the entire section and for the flanges and the web

\begin{tabular}{lccc}
\hline & $\rho_{v} \%$ total $*$ & $\begin{array}{c}\rho_{v} \% \text { of confined } \\
\text { region }\end{array}$ & $\begin{array}{c}\rho_{v} \% \text { of unconfined } \\
\text { region }\end{array}$ \\
\hline Flange with distributed reinforcement layout (East flange) & $1.06 \%$ & $1.34 \%$ & $0.91 \%$ \\
Flange with concentrated reinforcement layout (West flange) & $1.01 \%$ & $2.45 \%$ & $0.31 \%$ \\
Web & $1.16 \%$ & $1.25 / 0.90 \% * *$ & $1.00 \%$ \\
Entire wall & $1.09 \%$ & - & - \\
\hline
\end{tabular}

* Total reinforcement percentage for the flanges and the web was computed by counting the corners towards the web.

** Due to differences in flange reinforcement layouts, reinforcement contents of confined corner regions are slightly different.

Table 2 Mean values and standard deviations of mechanical properties of concrete

\begin{tabular}{cccccccc}
\hline & \multicolumn{2}{c}{ Compressive strength tests } & \multicolumn{2}{c}{ E-modulus and compressive strength tests } & \multicolumn{2}{c}{ Double-punch tests } \\
\hline & $\begin{array}{c}f_{c}^{\prime}-28 \text { days } \\
{[\mathrm{MPa}]}\end{array}$ & $\begin{array}{c}\text { No. of } \\
\text { samples }\end{array}$ & $\begin{array}{c}f_{c}^{\prime} \\
{[\mathrm{MPa}]}\end{array}$ & $\begin{array}{c}E_{c} \\
{[\mathrm{GPa}]}\end{array}$ & $\begin{array}{c}\text { No. of } \\
\text { samples }\end{array}$ & $\begin{array}{c}f_{t}^{\prime} \\
{[\mathrm{MPa}]}\end{array}$ & $\begin{array}{c}\text { No. of } \\
\text { samples }\end{array}$ \\
\hline TUC & $38.1 \pm 0.7$ & 3 & $42.0 \pm 1.4$ & $31.6 \pm 3.9$ & 3 & $3.2 \pm 0.2$ & 4 \\
TUD & $37.0 \pm 1.3$ & 3 & $41.5 \pm 1.2$ & $30.3 \pm 0.8$ & 4 & $3.0 \pm 0.2$ & 4 \\
\hline
\end{tabular}

Table 3 Mean values and standard deviations of mechanical properties of reinforcement bars used for TUC and TUD

\begin{tabular}{lcccccc}
\hline & $f_{y}[\mathrm{MPa}]^{*}$ & $f_{u}[\mathrm{MPa}]$ & $f_{u} / f_{y}[-]$ & $\mathcal{E}_{s h}[\%]$ & $\mathcal{E}_{s u}[\%]$ & No. of samples \\
\hline D6mm bars & $492 \pm 5.1$ & $623 \pm 8.7$ & $1.26 \pm 0.02$ & - & $6.8 \pm 0.9$ & 6 \\
D8mm bars & $563 \pm 26.6$ & $663 \pm 6.5$ & $1.18 \pm 0.05$ & - & $7.9 \pm 0.8$ & 7 \\
D12mm bars & $529 \pm 4.7$ & $633 \pm 3.9$ & $1.19 \pm 0.01$ & $2.4 \pm 0.25$ & $9.6 \pm 1.2$ & 3 \\
\hline
\end{tabular}

$*$ The yield strength $f_{y}$ was determined at the $0.2 \%$ strain offset $(0.2 \%$ proof stress $)$

\subsection{Description of test setup and instrumentation}

A photo of the test setup is shown in Figure 2a. As in Beyer et al. [2], the walls were loaded horizontally with three actuators: the EW actuator loaded the webs at a height of $h_{E W}=3.35 \mathrm{~m}$ while the NS actuators loaded the flanges of the wall at a height of $h_{N S}=2.95 \mathrm{~m}$ from the foundation (see also Figure 1). The tests were performed in displacement control and rotation at the top of the wall was restrained by applying equal displacements with the NS-W and NS-E actuators. The axial load was applied by a tendon pre-tensioned by a hollow core jack located on a bream at the top of the wall (Figure 2a). The pressure in the hollow core jack was kept constant and therefore the test unit was subjected to a constant axial load throughout the testing (maximum variation: $-2.5 \%$ to $6.4 \%$ ). During testing, the wall behaviour was monitored through conventional instruments 
(linear variable differential transducers (LVDTs) and load cells) and through an optical measurement system based on triangulations of active light emitting diodes (LEDs). Photos, manual measurements of cracks and hand notes completed the data collected during the test. The layout of the measurement systems is shown in Figure 2b. LVDTs were used to measure global horizontal displacements at the top of the wall as well as the vertical elongation of the wall edges, which were recorded by means of four chains of eight LVDT devices each. This instrumentation is the same as the one used in [2]. One chain of four LVDTs was added on the inner side of each flange end to capture the vertical strain variation through the thickness of the flange.

The optical measurement system Optotrak Certus [10] was composed of active LEDs (466 LEDs for TUC and 510 LEDs for TUD) and three position sensors recording the 3D coordinates of the LEDs with a frequency of $2 \mathrm{~Hz}$. The LEDs were glued on the outer faces of the wall in regular grids of 100x125 mm (TUC) and 100x100 mm (TUD) to match vertical and horizontal reinforcement spacing (Figure 2). One row of LEDs was also glued on the foundation in order to record foundation uplift and sliding. The height of the LED grid extended up to $\sim 1.7 \mathrm{~m}$ above the foundation as the main interest was to capture the plastic zone of the wall while respecting the measurement volume of the optical system.

(a)

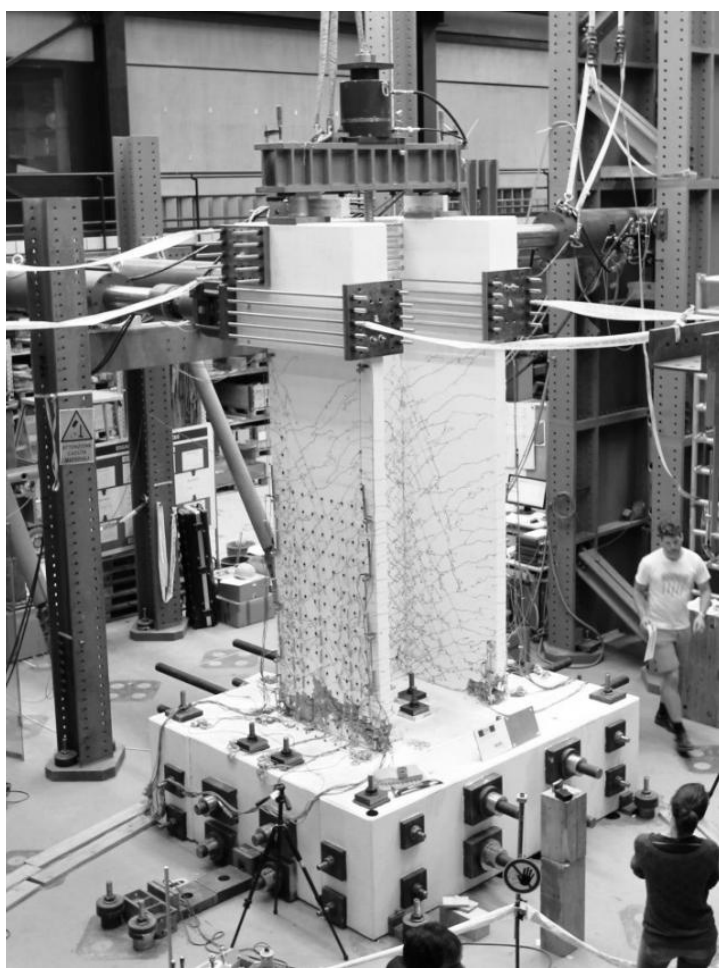

(b)

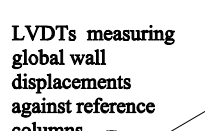

against reference columns -

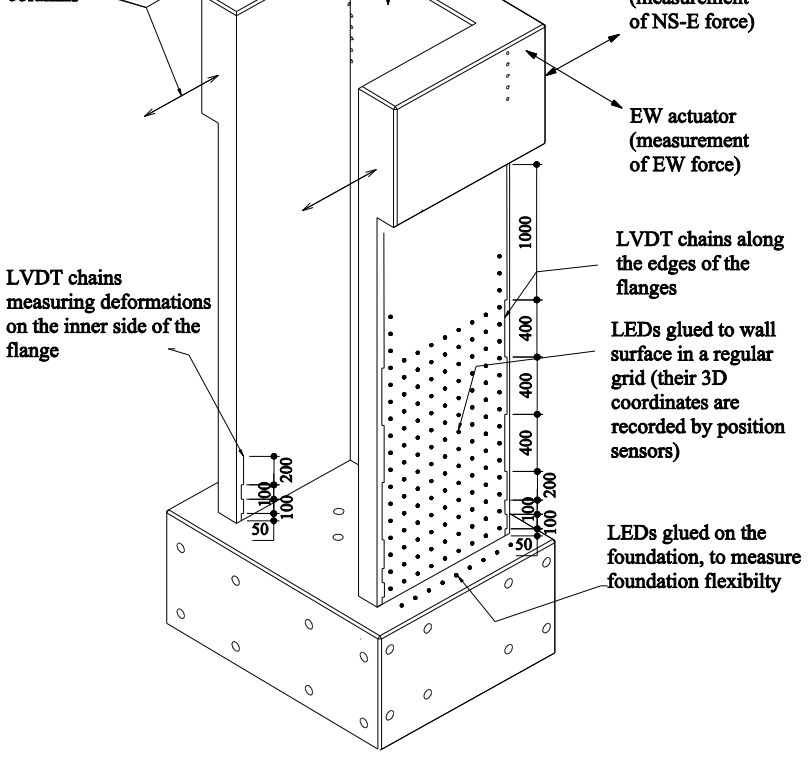

Figure 2 Photo of the test setup (a) and location of the conventional and optical measurement devices (b) 


\subsection{Loading history}

As stated in the introduction, the key objective was to understand the behaviour of the wall under diagonal loading. Hence, the main cycles were applied along the two geometric diagonals of the U-shaped section. The direction of the geometric diagonal joins the outer corner between web and flange with the outer edge of the flange end (Figure $3 b-$ directions E-F and $\mathrm{H}-\mathrm{G})$. Cycles along the principal directions, i.e., loading parallel to the web (EW direction with positions A and B - Figure 3) or loading parallel to the flanges (NS direction with positions C and D - Figure 3), were also added at small drift levels in order to check the strength capacity of the wall in these directions, as past tests have shown that for these directions the strength capacity can be predicted using the plane section hypothesis [2]. The loading positions are shown in Figure $3 \mathrm{~b}$ while the loading history of the test units is described below and shown in Figure 4.

- $\quad 0.1 \%$ drift: $\mathrm{O} \rightarrow \mathrm{C} \rightarrow \mathrm{D} \rightarrow \mathrm{O} \rightarrow \mathrm{A} \rightarrow \mathrm{B} \rightarrow \mathrm{O}$

- $\quad 0.2 \%$ drift: $\mathrm{O} \rightarrow \mathrm{C} \rightarrow \mathrm{D} \rightarrow \mathrm{O} \rightarrow \mathrm{A} \rightarrow \mathrm{B} \rightarrow \mathrm{O} \rightarrow \mathrm{E} \rightarrow \mathrm{F} \rightarrow \mathrm{O} \rightarrow \mathrm{H} \rightarrow \mathrm{G} \rightarrow \mathrm{O}$

- $0.3 \%, 0.4 \%, 0.6 \%$ drifts: $\mathrm{O} \rightarrow \mathrm{E} \rightarrow \mathrm{F} \rightarrow \mathrm{O} \rightarrow \mathrm{H} \rightarrow \mathrm{G} \rightarrow \mathrm{O} \rightarrow \mathrm{C} \rightarrow \mathrm{D} \rightarrow \mathrm{O} \rightarrow \mathrm{A} \rightarrow \mathrm{B} \rightarrow \mathrm{O}$

- $\quad 0.8 \%$ drift: $\mathrm{O} \rightarrow \mathrm{C} \rightarrow \mathrm{D} \rightarrow \mathrm{C} \rightarrow \mathrm{D} \rightarrow \mathrm{O} \rightarrow \mathrm{A} \rightarrow \mathrm{B} \rightarrow \mathrm{A} \rightarrow \mathrm{B} \rightarrow \mathrm{O}$

- $1.0 \%, 2.0 \%, 3.0 \%$ drifts: $\mathrm{O} \rightarrow \mathrm{E} \rightarrow \mathrm{F} \rightarrow \mathrm{E} \rightarrow \mathrm{F} \rightarrow \mathrm{O} \rightarrow \mathrm{H} \rightarrow \mathrm{G} \rightarrow \mathrm{H} \rightarrow \mathrm{G} \rightarrow \mathrm{O}$

- $1.5 \%, 2.5 \%$ drifts: $\mathrm{O} \rightarrow \mathrm{H} \rightarrow \mathrm{G} \rightarrow \mathrm{H} \rightarrow \mathrm{G} \rightarrow \mathrm{O} \rightarrow \mathrm{E} \rightarrow \mathrm{F} \rightarrow \mathrm{E} \rightarrow \mathrm{F} \rightarrow \mathrm{O}$

From $1.0 \%$ drift onwards, two complete reverse cycles were applied for each diagonal direction at each drift level. The orientation of the first diagonal applied at a new drift level alternated between the E-F direction and the H-G direction.

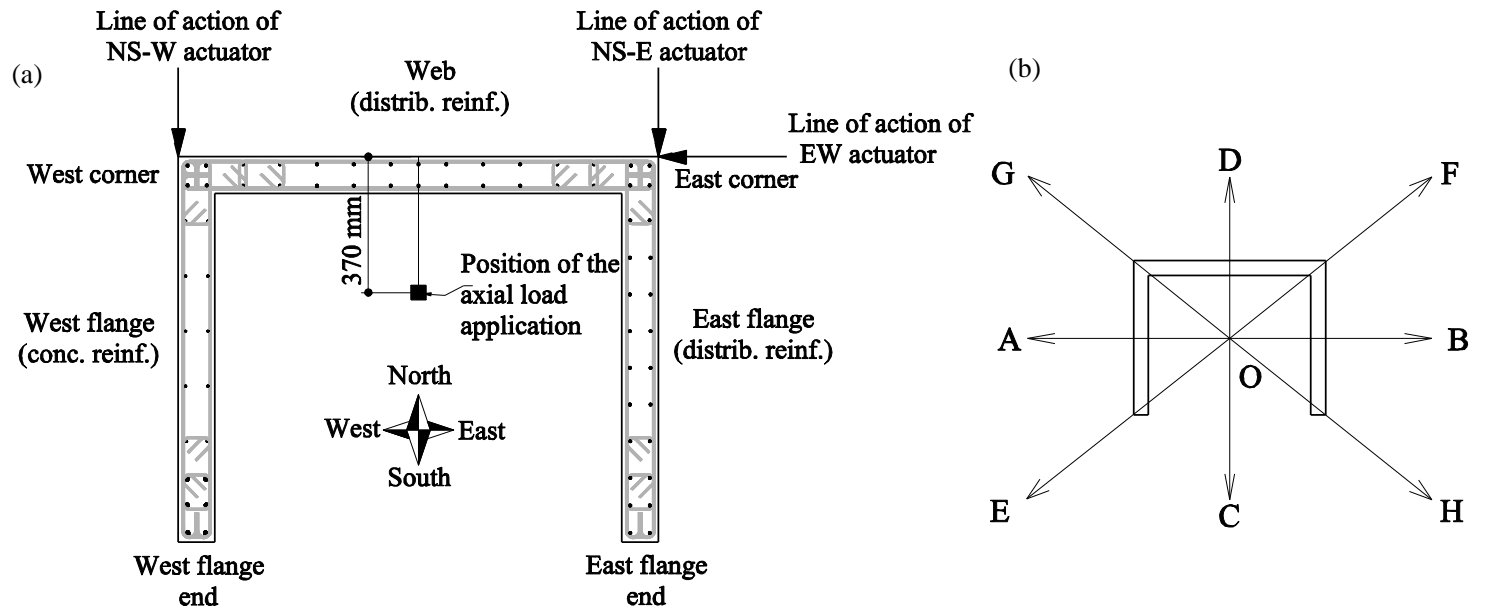

Figure 3 Cardinal points, sign convention for forces and displacements, denomination of wall parts (a) and loading positions (b) 


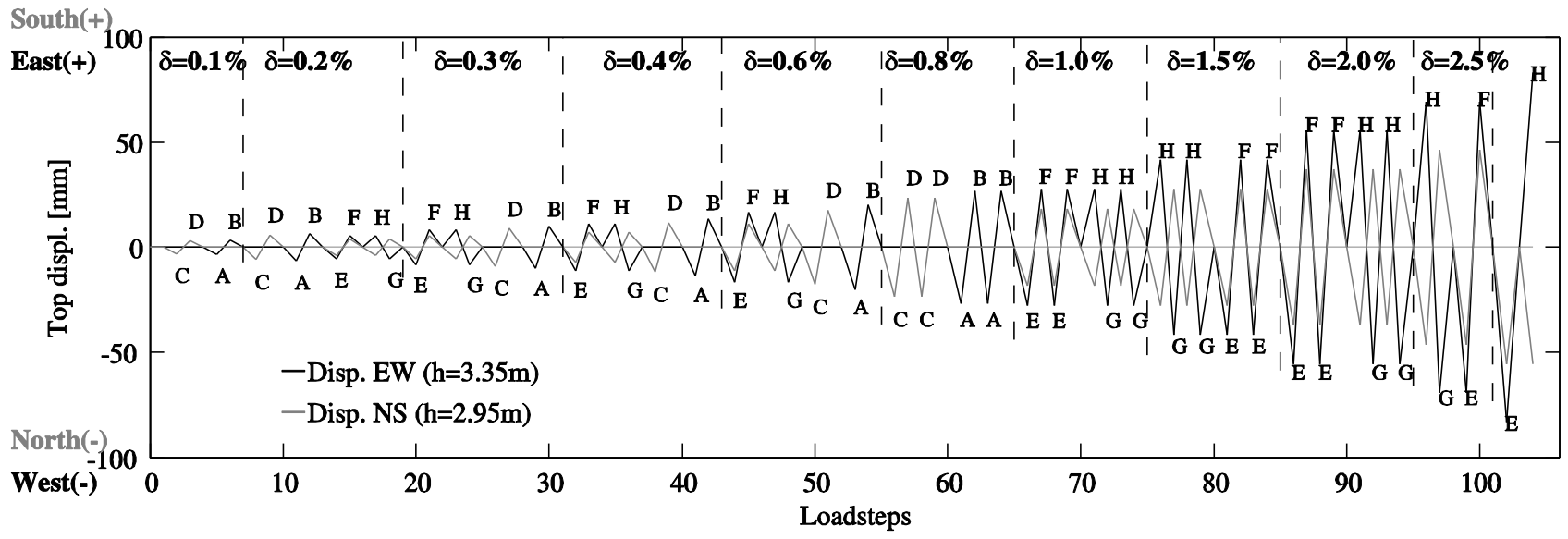

Figure 4 TUC loading history

Towards the end of the tests, the loading was only continued along the diagonal that led still to a stable hysteretic behaviour, as extensive wall damage had significantly reduced the stiffness in the other diagonal. The modified protocols at the end of the test were as follows:

Modifications to load protocol TUC:

- $2.5 \%$ drift: $\mathrm{O} \rightarrow \mathrm{H} \rightarrow \mathrm{G} \rightarrow \mathrm{O} \rightarrow \mathrm{E} \rightarrow \mathrm{F} \rightarrow \mathrm{O}$

- $\quad 3.0 \%$ drift: $\mathrm{O} \rightarrow \mathrm{E} \rightarrow \mathrm{O} \rightarrow \mathrm{H} \rightarrow \mathrm{O}$ (test was stopped due to loss of vertical load bearing capacity)

Modifications to load protocol TUD:

- $1.5 \%$ drift: $\mathrm{O} \rightarrow \mathrm{H} \rightarrow \mathrm{G} \rightarrow \mathrm{H} \rightarrow \mathrm{O} \rightarrow \mathrm{E} \rightarrow \mathrm{F} \rightarrow \mathrm{E} \rightarrow \mathrm{O}$ (test was stopped due to loss of vertical load bearing capacity)

\section{Test results}

In this section the most important findings from the tests are presented. Failure mechanisms together with hysteretic behaviour are discussed in Section 3.1. The influence of the reinforcement layout and of the axial load on the crack pattern and crack widths is shown in Section 3.2. Local deformation response specific to U-shaped walls under diagonal loading is presented in Section 3.3, while Section 3.2 investigates the influence of the vertical reinforcement layout and the axial load ratio on the shear to flexural deformation ratios.

\subsection{Failure mechanisms and hysteretic behaviour}

The failure mechanisms of the two test units are illustrated in Figures 5 to 7 while the force-displacement hystereses are shown in Figures 8 to 9. For the two diagonal directions individual actuator forces as well as their resultant are plotted against 
the wall top displacements, which were measured by means of the horizontal LVDTs recording the NS displacements at $h_{N S}=$ $2.95 \mathrm{~m}$ and the EW displacements at both $h_{N S}$ and $h_{E W}=3.35 \mathrm{~m}$. The top displacements were corrected for the foundation flexibility (uplift and sliding) by subtracting the top displacements due to foundation flexibility.

Foundation flexibility resulted from the uplift and the sliding of the wall foundation with respect to the laboratory strong floor. The uplift and sliding of the foundation was computed from the LEDs glued on the foundation (LEDs on small steel angle in Figure 2). Top displacement due to uplift was computed assuming a rigid body rotation of the wall and the foundation, while the top displacement due to sliding was simply taken equal to the sliding displacement measured between the foundation and the laboratory strong floor. Top displacements due to foundation flexibility accounted for $\sim 6-8 \%$ of the measured top displacements at yield drift and decreased thereafter. The corrected top displacements and the forces were combined through the square root of the sum of squares (SRSS) to obtain quantities representative of the diagonal directions (Figures $8 b-c$ and 9b-c):

$$
\begin{gathered}
F_{S R S S}=\sqrt{F_{E W}^{2}+{F_{N S}}^{2}} * \operatorname{sign}\left(\Delta_{N S}\right) \\
\Delta_{S R S S}=\sqrt{\left(\Delta_{N S}^{2}+\Delta_{E W @ 2.95}{ }^{2}\right)} * \operatorname{sign}\left(\Delta_{N S}\right)
\end{gathered}
$$

where $\mathrm{F}_{\mathrm{EW}}$ and $\mathrm{F}_{\mathrm{NS}}$ are the forces carried by the wall in the EW and the NS direction respectively, while $\Delta_{E W @ 2.95}$ and $\Delta_{N S}$ are

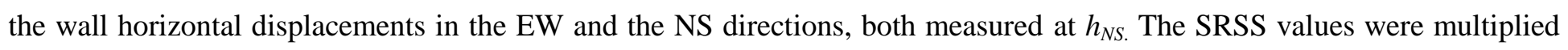
by the sign of the NS displacement for plotting the hysteresis loops consistently.

\subsubsection{TUC}

Failure mode when loading along the diagonal E-F: Failure of TUC occurred due to out-of-plane buckling and compression failure of the flange with the concentrated reinforcement (West flange). Failure occurred during loading in the E-F diagonal direction when the flange end was in compression at position E (Figure 5). A maximum of 2.5\% SRSS drift was reached for this direction prior to wall failure. During the last cycle, the wall stiffness was significantly reduced when loading from zero displacement towards position E, as compared to the previous cycles at the same loading position (Figure 8b, d-f). In this 
cycle the loading was stopped at only $1.0 \%$ drift due to extensive damage to the West flange and $\sim 35 \%$ drop in the SRSS force capacity as compared to the maximum reached in this last cycle at this loading position (see Figure 8b).

Out-of-plane failure of plastic zone of West flange: The failure mode of the wall, i.e. out-of-plane buckling of the wall end and compression failure of the unconfined concrete, was first experimentally investigated and reported by Paulay and Goodsir [11] for walls loaded in plane. For TUC, the evolution of wall failure can be summarised as follows: due to large displacement demands imposed on the wall at position F (i.e., 2.5\% SRSS drift), large tensile strains were developed in the reinforcement bars of the West flange end resulting in wide horizontal cracks $(\sim 4 \mathrm{~mm})$ in this region. When unloading from position F, the longitudinal bars first had to yield in compression before the cracks could close. During this stage the plastic zone had a very small stiffness and was as a result vulnerable to out-of-plane instability.

For rectangular walls loaded in plane, out-of-plane displacements are typically caused mainly by construction imperfection. Loading to position E led to a large strain gradient across the flange end (see Section 3.3.1), which leads to an eccentricity of the compression force acting in this region. This strain gradient is expected to have promoted the out-of-plane buckling process. As a result of the strain gradient, the flange end bulged towards the inside of the U-shaped wall, which was also the direction in which the flange failed out-of-plane (Figure 5b).

Based on the visual observation and the force-displacement hystereses, the initiation of the out-of-plane buckling occurred near zero SRSS top displacement when returning to zero from the first cycle at position F with $2.5 \%$ SRSS drift. The forcedisplacement hystereses show significantly reduced wall stiffness after the onset of buckling (Figure 8b, d-f). The fact that onset of buckling occurred near zero displacement is in line with observations from tests on thin T-shaped walls, which failed also due to out-of-plane buckling ([12]). It was found that at this instant, cracks are open along the entire length of the wall and the out-of-plane stiffness is therefore very small. Note that, while the out-of-plane buckling mode of TUC and the thin walls described in [12] shared many similarities, the buckling mode of the thin walls involved the entire storey height and not just the plastic zone as observed for TUC.

Due to the out-of-plane buckling, the West flange end of TUC lost its compression carrying capacity. To compensate for this, the compressed depth increased into the unconfined part of the flange, leading to concrete crushing in this region and final 
loss of the wall force capacity both in the direction of the flanges (NS direction - Figure 8d-e) and also in the direction of the web (EW direction - Figure 8f).

Failure mode when loading along the diagonal $\mathrm{H}$-G: Continuing loading along the E-F diagonal would have led to a complete destruction of the West flange due to the out-of-plane buckling compression failure at $1.0 \%$ drift. For this reason, this loading cycle was not completed and the wall was cycled along the H-G diagonal instead. However, loading along this diagonal led to a compression failure of the East flange at $2.5 \%$ SRSS drift, which had already been reached in a previous cycle. At this point the test was stopped because of axial load failure (Figure 6 and Figure 8g-i).
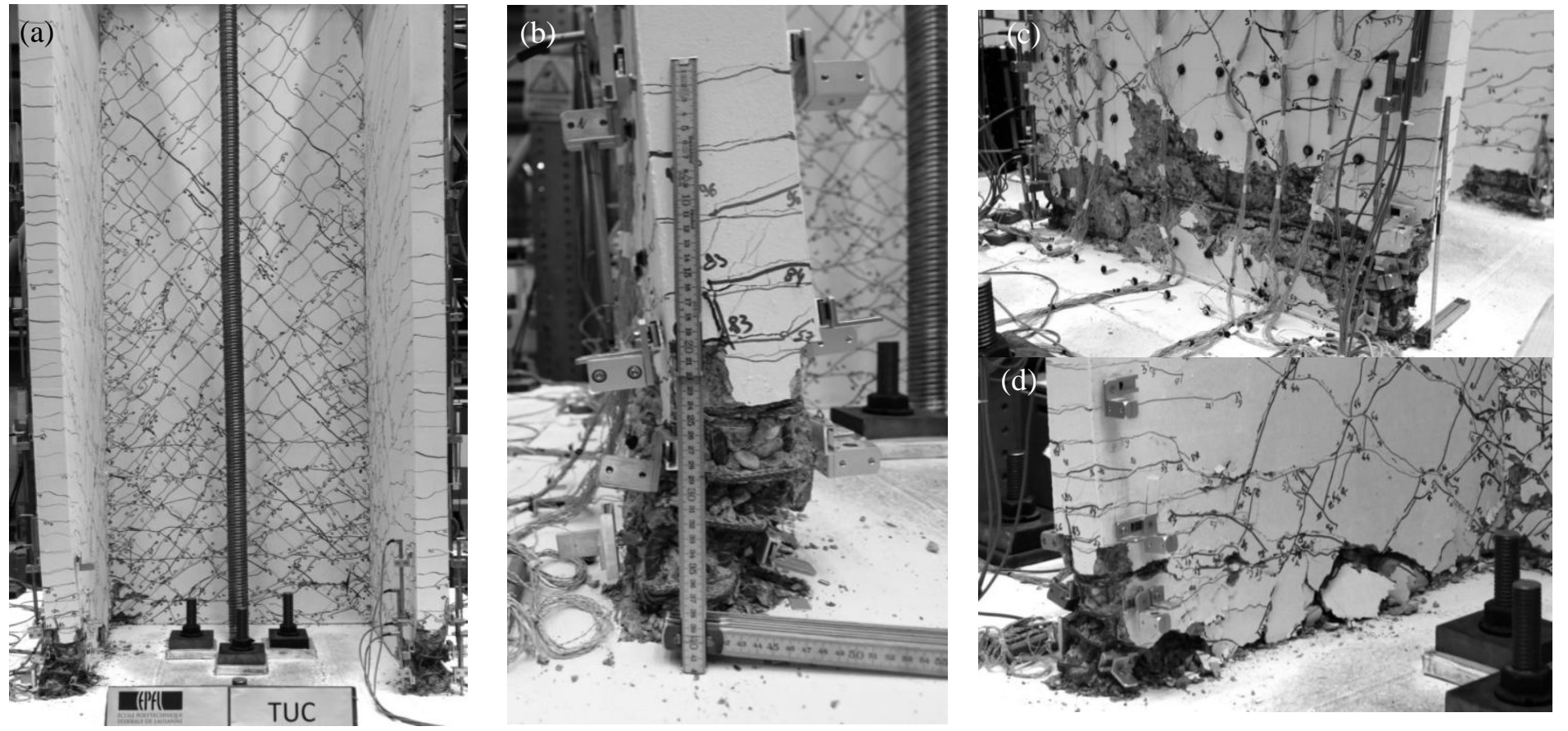

Figure 5 TUC: Out-of-plane buckling and compression failure of the concentrated reinforcement layout flange at position E (West flange end in compression) at an SRSS drift of $\sim 1.0 \%$. Front view of the wall (a); close-up view of the buckled flange end (b); outside view (c) and inside view (d) of the West flange
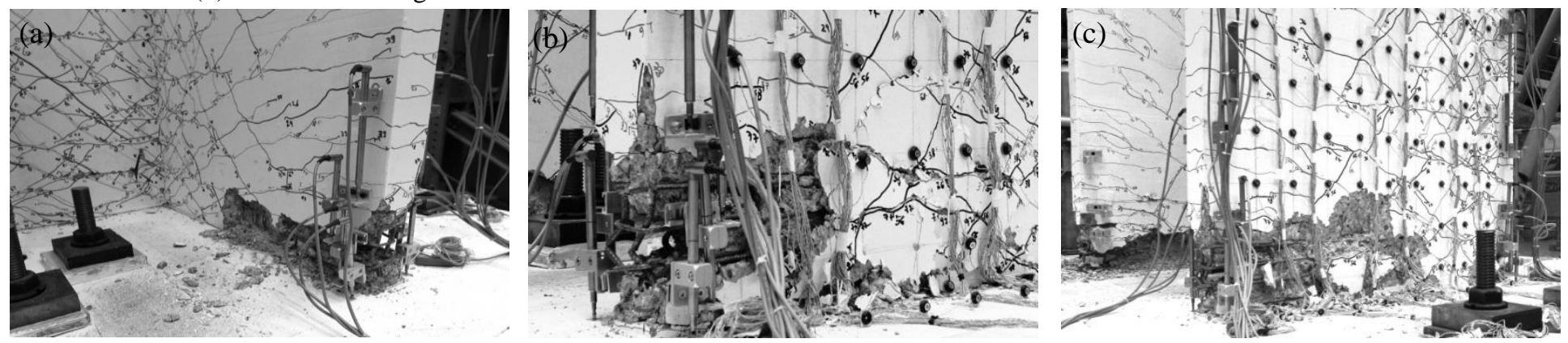
Figure 6 TUC: Crushing of the concrete in the flange with distributed reinforcement (East) at position $\mathrm{H}$ (East flange end in compression) at an SRSS drift of $\sim 2.5 \%$. View for inner side of the East flange (a) and view from the outer side: far-off view (b) and close-up

Influence of reinforcement layout on buckling of longitudinal bars: Recent experimental research on rectangular walls [13] concluded however that walls detailed with distributed reinforcement will reach lower ultimate drifts than walls with concentrated reinforcement, as the smaller diameter bars in the boundary elements of the former will undergo early bar buckling for the same stirrup spacing of the two walls. The failure of the U-shaped walls presented here was, however, not controlled by bar fracture. The different diameters of longitudinal reinforcement bars in the flanges with concentrated (West) and distributed reinforcement (East) had, however, an influence on the onset of bar buckling and the drift at which first bar fractures were observed.

Three of the four confined boundary elements of the U-shaped walls were detailed with D8 vertical reinforcement bars, i.e., the end of the flange with distributed reinforcement (East) and the two corners between a flange and the web. The fourth boundary element, i.e., the end of the flange with concentrated reinforcement (West) was detailed with D12 vertical bars. All four boundary elements featured the same stirrup spacing (Figure 1a). D8 bars of the boundary elements buckled indeed before any D12 bar of the West flange end buckled (Figure 10b): Two D8 bars first buckled in the East flange end in the first cycle at $1.5 \%$ drift at position $\mathrm{H}$ followed by the buckling of one D8 bar in the confined corner between East flange and web in the second cycle at $2.0 \%$ drift at position F. In the confined corner between West flange and web one D8 bar first buckled in the first cycle at $2.0 \%$ drift at position G. In the following cycles, further D8 bars buckled in these confined boundary elements. And finally, buckling initiated also in the West flange end when a D12 bar buckled in the cycle at $2.5 \%$ drift at position E. Outside the boundary elements, bar buckling occurred only in the unconfined concrete of the flange with concentrated reinforcement (West). For this flange the outer D6 bar closest to the confined flange end buckled in the first cycle at $2.5 \%$ drift at position $\mathrm{G}$, hence before any buckling occurred in end of this flange.

Bar fractures first occurred in the cycle at $2.5 \%$ drift at position $\mathrm{G}$ when three D8 bars fractured in the East flange end. Their fracture however did not significantly affect the wall strength, i.e., the wall retained more than $80 \%$ of its SRSS force capacity (Figure 8c, g-i) and also of the NS force capacity (Figure 8d), and was hence not considered as failure. The strength drop was not significant since bar diameters are small and uniformly distributed throughout the flange. 
Influence of the reinforcement layout on the wall stability: The observed failure modes suggested that the flange with distributed reinforcement layout (East flange) was less prone to out-of-plane buckling failure than the flange with concentrated reinforcement layout (West flange). Mechanical models by Paulay and Priestley [14] and Chai and Elayer [15] show that the lateral stability of the wall boundary element depends strongly on the maximum tensile strain the wall boundary element had been subjected to. This threshold value of tensile strain that triggers the out-of-plane instability decreases with increasing vertical reinforcement ratio ([15]-[16]). As a result, flange ends with large vertical reinforcement contents—-such as those in sections with concentrated reinforcement layout — are more susceptible to out-of-plane buckling than flange ends of sections with lower vertical reinforcement contents as in distributed reinforcement layouts [16]. This trend is in line with the observed flange failures.

Drift capacities: Along both diagonals, one full cycle with $2.5 \%$ SRSS drift was completed before the strength dropped by $20 \%$ or more. For the test here, the wall flange with distributed and the wall flange with concentrated reinforcement reached the same drift capacity. The failure modes attained for the two loading directions were, however, rather different and strongly influenced by the respective reinforcement layouts. Based on the test observations the reinforcement layouts influence the following phenomena:

- The drift related to the onset of bar buckling and bar fracture: For distributed reinforcement layouts, the diameter of the longitudinal bars in the boundary elements is typically smaller than for concentrated reinforcement layouts. For the same stirrup spacing, bars in the distributed reinforcement layout will therefore buckle and fracture at smaller drifts.

- The out-of-plane stability of the plastic zone: The larger the vertical reinforcement content in the boundary element, the more prone is the plastic zone to out-of-plane instability. For TUC, out-of-plane instability occurred for the West flange (concentrated reinforcement) but not for the East flange (distributed reinforcement).

The influence of the reinforcement layout on crack widths and shear deformations is discussed in Sections 3.2 and 3.4 respectively. For TUD the reinforcement layout had also an influence on the compression zone depth, which is discussed in the following section. 


\subsubsection{TUD}

TUD, the test unit with an axial load ratio of 0.15 , failed due to an explosive compression failure of the concrete in the flange with distributed reinforcement (East flange, Figure $7 \mathrm{~b}-\mathrm{c}$ ). The compression failure occurred after reaching position $\mathrm{H}$ in the second cycle at $1.5 \%$ drift (Figure 9c, g-i). The compression failure initiated in the confined part of the flange end and extended suddenly to the unconfined part of the flange. Once the behaviour stabilised again, the flange had crushed along $\sim 80 \%$ of its length (Figure $7 \mathrm{c}$ ). In the previous cycle, visual inspection indicated only limited crushing of the boundary element as shown in Figure 7a.

The explosive failure and the extensive concrete crushing were caused by the large compression depth and significant compressive strains in the East flange at position $\mathrm{H}$. Already in the first cycle at position $\mathrm{H}$ at $1.5 \%$ drift, the compressive strains computed from optical measurements reached for the unconfined concrete of the flange $\sim 0.003$ (average strains over the height $h=75-200 \mathrm{~mm}$, h measured from top of foundation). Due to the larger axial load ratio the compression zone depth of TUD was larger than that of TUC. In addition, the distributed reinforcement layout in the East flange led to a larger compression zone depth for the East flange than for the West flange. But most importantly under diagonal loading with the flange end in compression (positions $\mathrm{E}$ and $\mathrm{H}$ ), the compression depth of the flange end is considerably larger than in the case of orthogonal loading with both flange ends in compression (position C) as local deformation response indicates (see Section 3.3.2).

For TUD, the wall failure along the H-G diagonal was marked by $\sim 75 \%$ loss in the SRSS force capacity (Figure $9 \mathrm{c}$ ). The loading was therefore continued in the E-F direction, but already in the first cycle concrete crushing in the web occurred leading to a significant strength drop at a drift of $\sim 1.0 \%$ (Figure 9f). Moreover, the wall was no longer able to carry the nominal axial load of $1950 \mathrm{kN}$.

The shear demand on TUD (SRSS force) was on average $\sim 36 \%$ larger than on TUC due to the increased axial load ratio of the former (Figure 8b-c and Figure 9b-c). The displacement capacity of TUD on the other hand was only $1.5 \%$ drift as compared to $2.5 \%$ drift for TUC. For TUC the failure was initiated by large out-of-plane deformations of the flange at zero SRSS drift (Figure 5) for TUD failure occurred at peak drift of a cycle when the flange failed suddenly leading to an extensive crushing band along almost the entire length of the flange (Figure $7 b-c)$. 

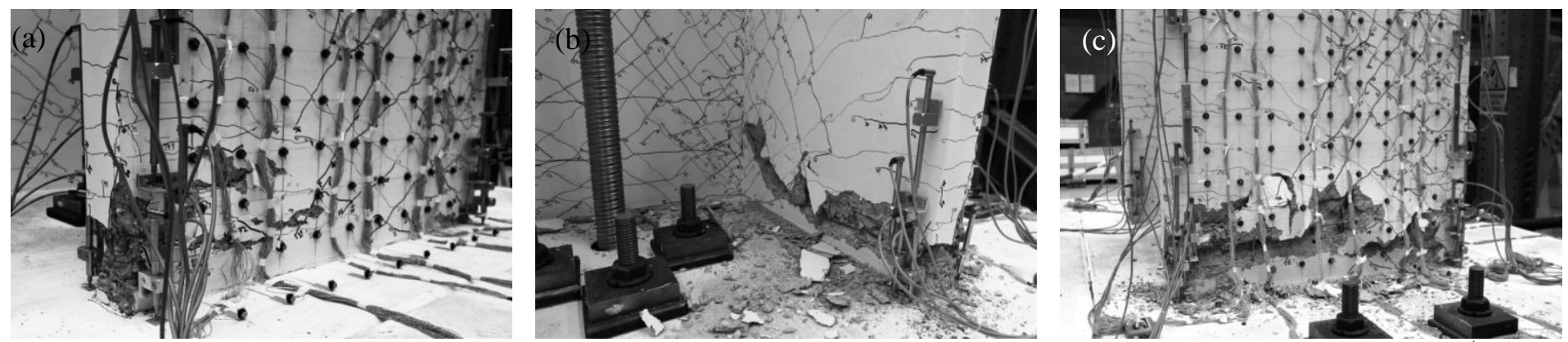

Figure 7 TUD: explosive compression failure of the distributed reinforcement layout flange (East flange). Wall condition at $1^{\text {st }}$ cycle at position $\mathrm{H}$ at $1.5 \%$ drift (a-b) and wall condition after failure in the $2^{\text {nd }}$ cycle at position $\mathrm{H}$ at $1.5 \%$ drift: view on the inner side (c) and view on the outer side $(\mathrm{d})$

(a)
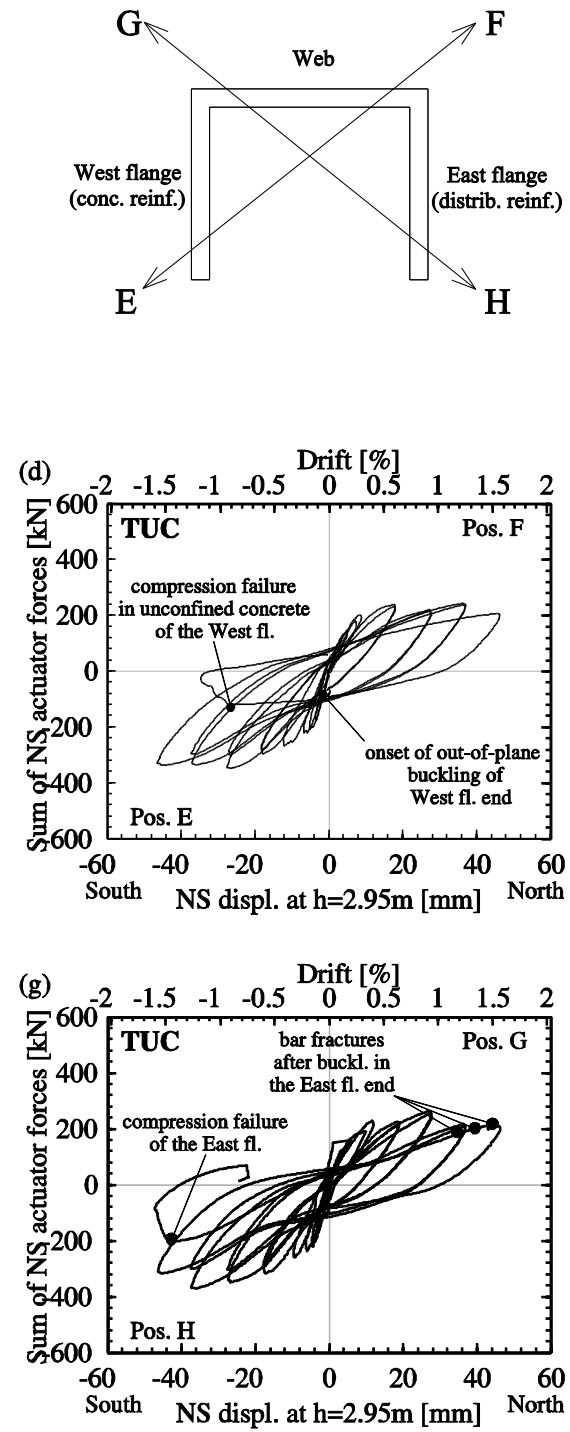

(b)

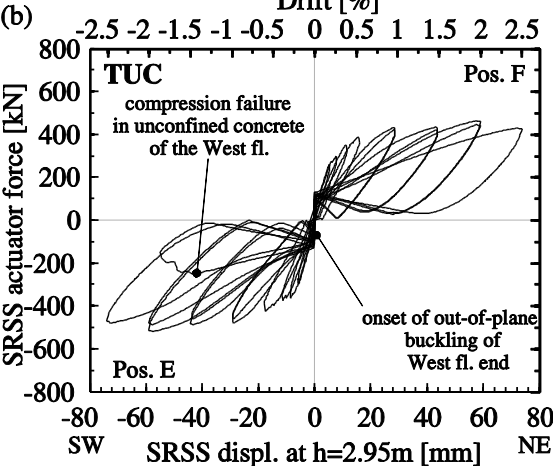

(e)

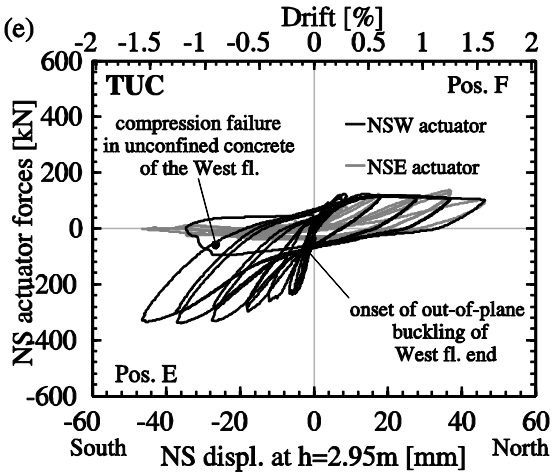

(h)

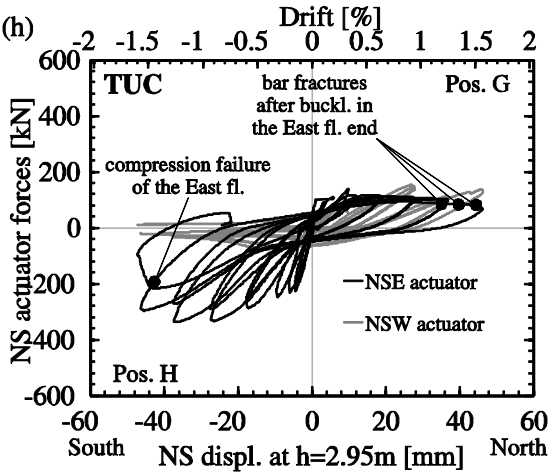

(c) Drift [\%]

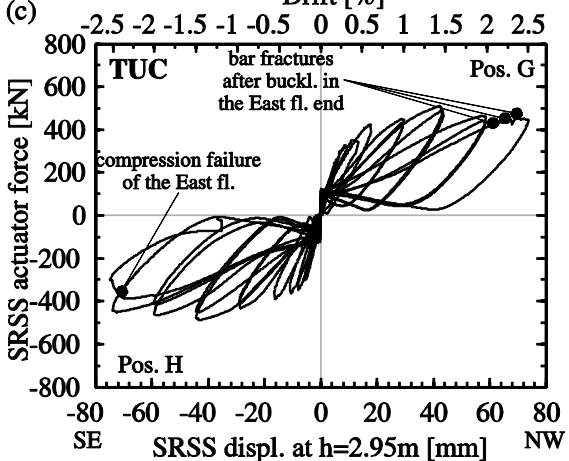

(f)
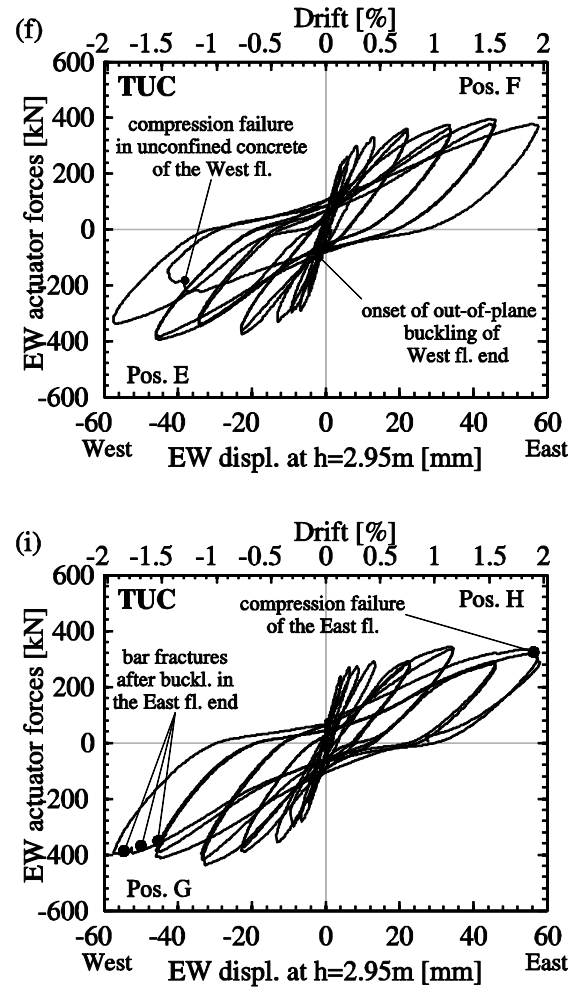

Figure 8 TUC: loading positions (a), SRSS force-displacement hystereses (b-c) and for individual NS and EW directions (d-i) 
(a)
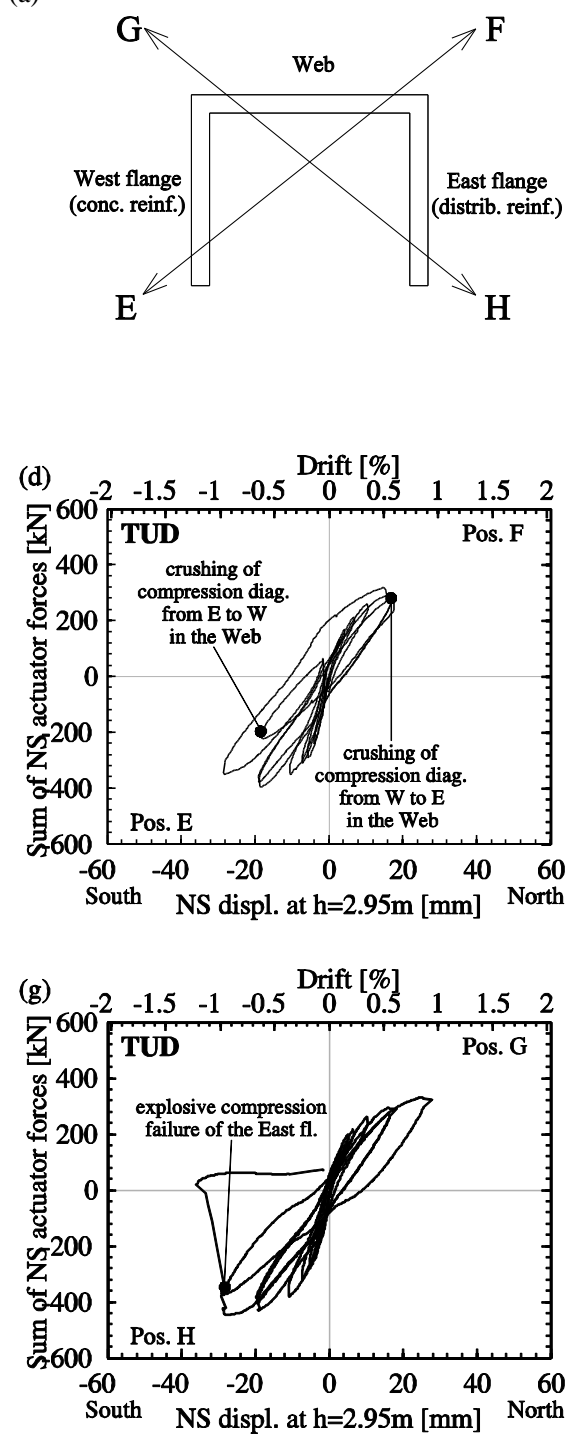

Drift $[\%]$

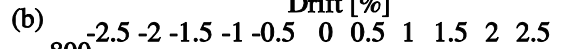

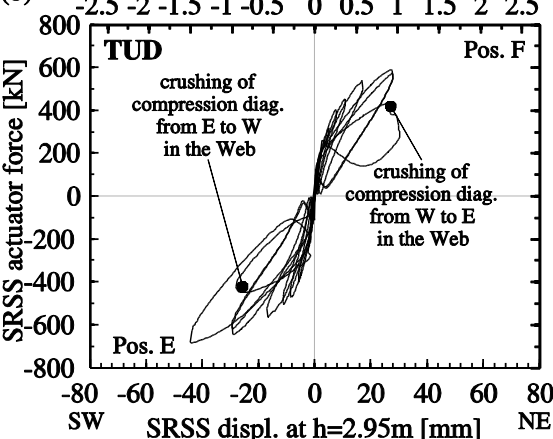

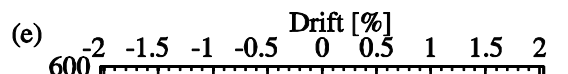
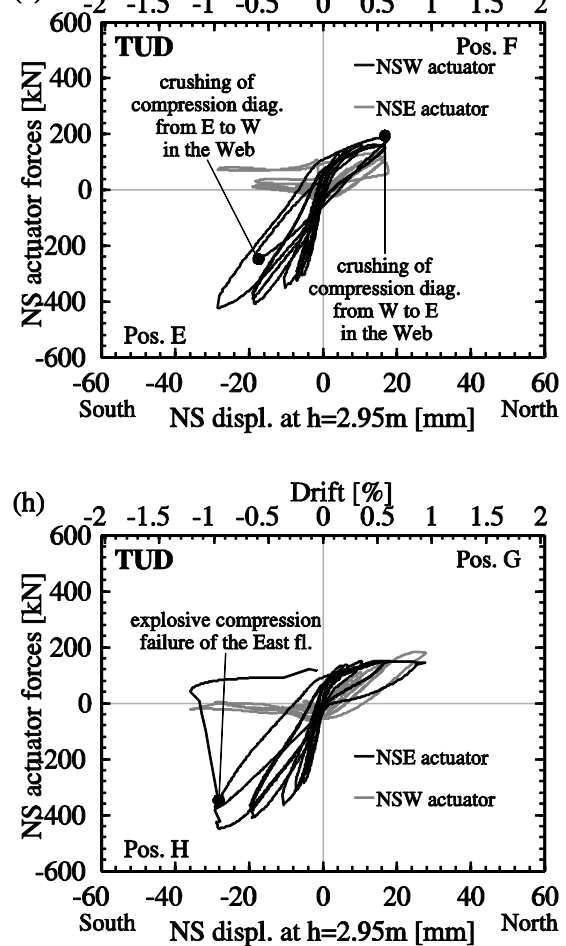

Drift [\%]

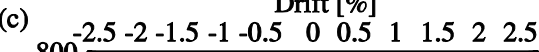
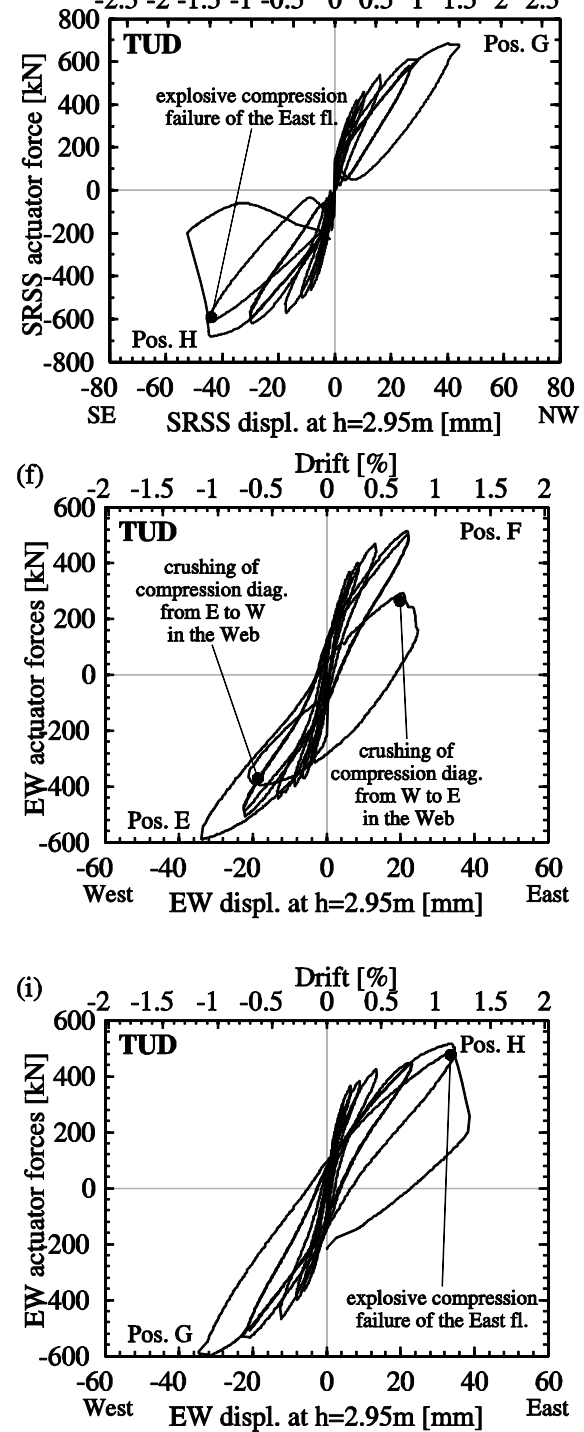

Figure 9 TUD: loading positions (a), SRSS force-displacement hystereses (b-c) and for individual NS and EW directions (d-i)

(a)

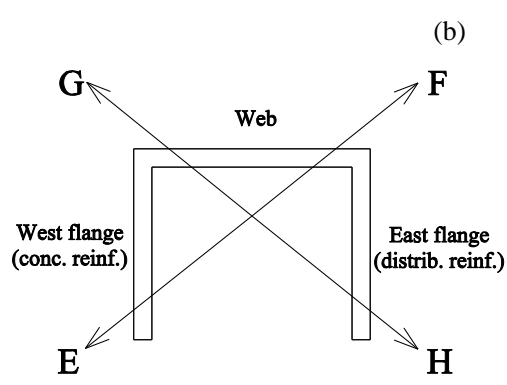

Figure 10 TUC: Sequence of bar buckling and fracture

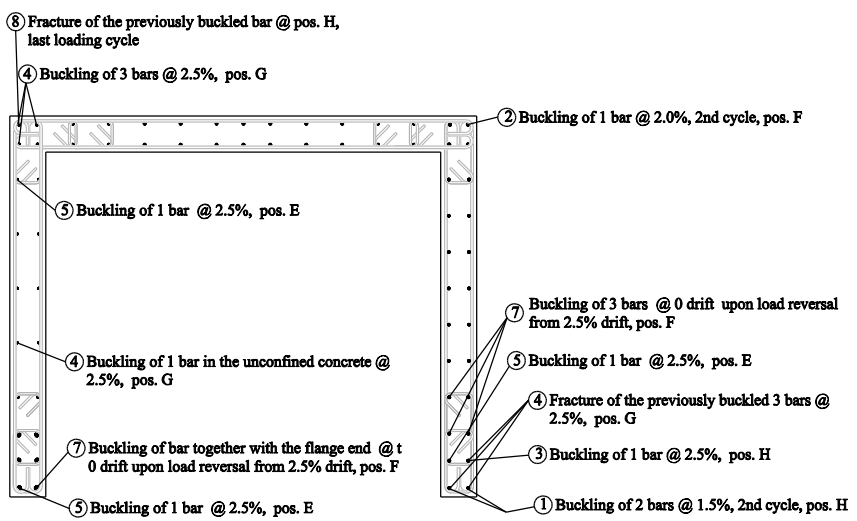




\subsection{Crack patterns}

The crack patterns for a U-shaped wall tested under different loading directions have already been discussed in detail elsewhere ([1]-[2]). Beyer et al. ([2]) observed in their tests, that in the web the crack patterns were similar to those encountered for typical rectangular walls while the flanges had the steepest cracks of the entire wall, which opened when the flanges were loaded along the diagonal directions towards positions $\mathrm{E}$ and $\mathrm{H}$. The steepest cracks in the web, opened in its half upper part also at positions $\mathrm{E}$ and $\mathrm{H}$. The same observations were found valid for the tests presented herein (Figures 11 and 12).

Since the two flanges of TUC and TUD were detailed with distributed and concentrated reinforcement layouts, the crack widths, spacing and the crack angles are of interest, as differences between the two flanges were expected. Previous numerical and experimental investigations on RC walls have shown that for concentrated reinforcement layouts, cracks in the unconfined concrete part have larger widths and larger crack spacing than in the distributed layout case ([3], [16] and [17]). During the testing of TUC and TUD, crack widths of selected cracks were measured manually at several load steps. The comparison of maximum crack widths in the unconfined concrete part of the two flanges under symmetric loading conditions for both flanges (i.e. Position $\mathrm{C}$ and Position D) is shown in Figure 13c-d up to $0.8 \%$ drift, the last drift where loading to these positions was applied. As expected, at Positions C and D, crack widths in the flange with concentrated reinforcement layout (West flange) were on average $40 \%$ larger than in the flange with distributed reinforcement layout (East flange). The inaccuracy of manual measurements for crack widths under $1 \mathrm{~mm}$, could explain the outliers in the graph: position C, drift $=0.6 \%$ and position $\mathrm{D}$, drift $=0.8 \%$. As a result of the differences in crack patterns, at the end of the test after both flanges underwent an equal number of loading cycles, the unconfined concrete of the concentrated layout flange was more damaged than the unconfined concrete of the distributed layout flange (Figure 13a-b). 

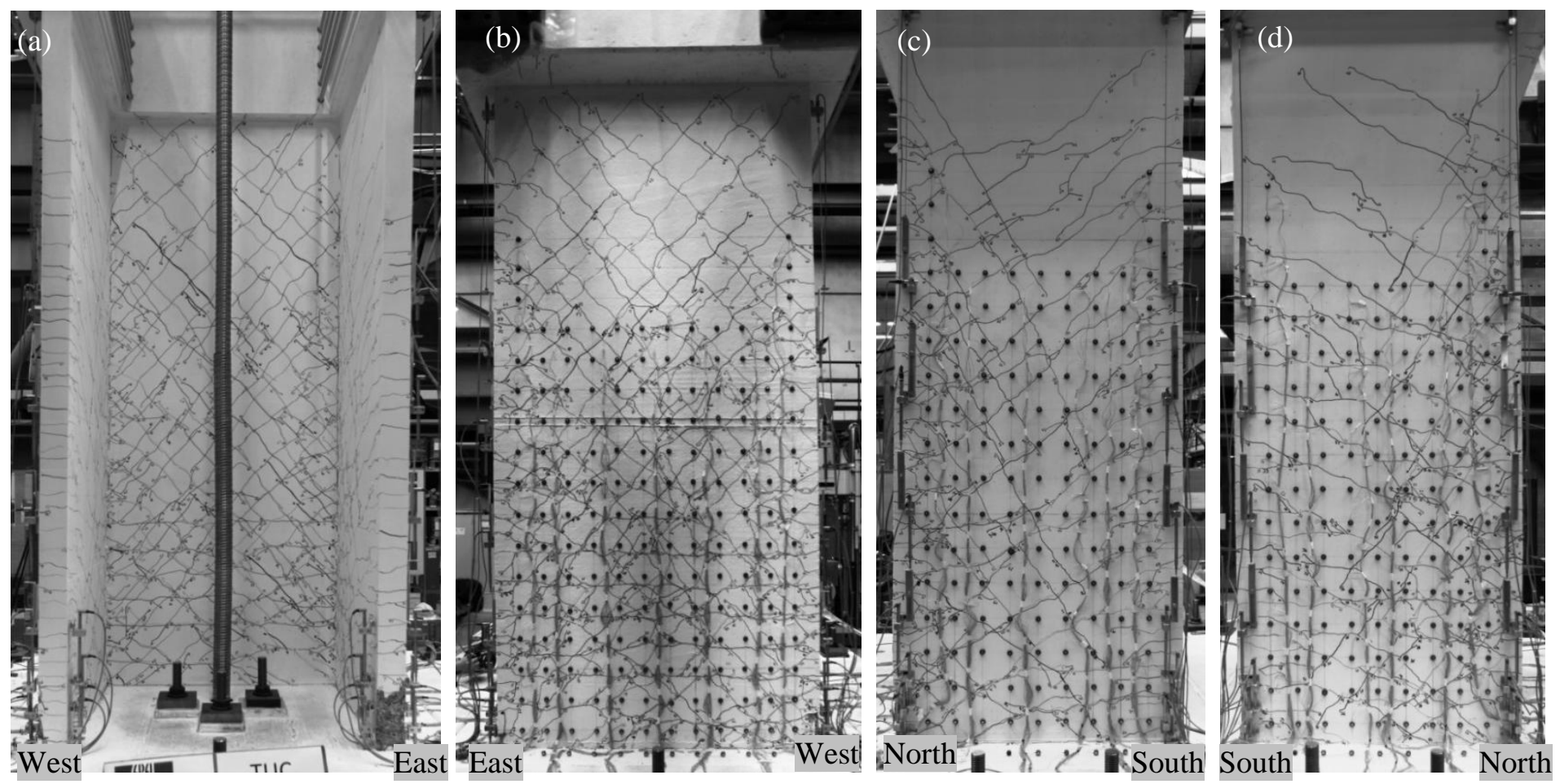

Figure 11 TUC: Crack patterns at the beginning of 1.5\% drift cycles: front view (a); back view (b); view of the West flange (concentrated reinforcement) (c) and view of the East flange (distributed reinforcement) (d)
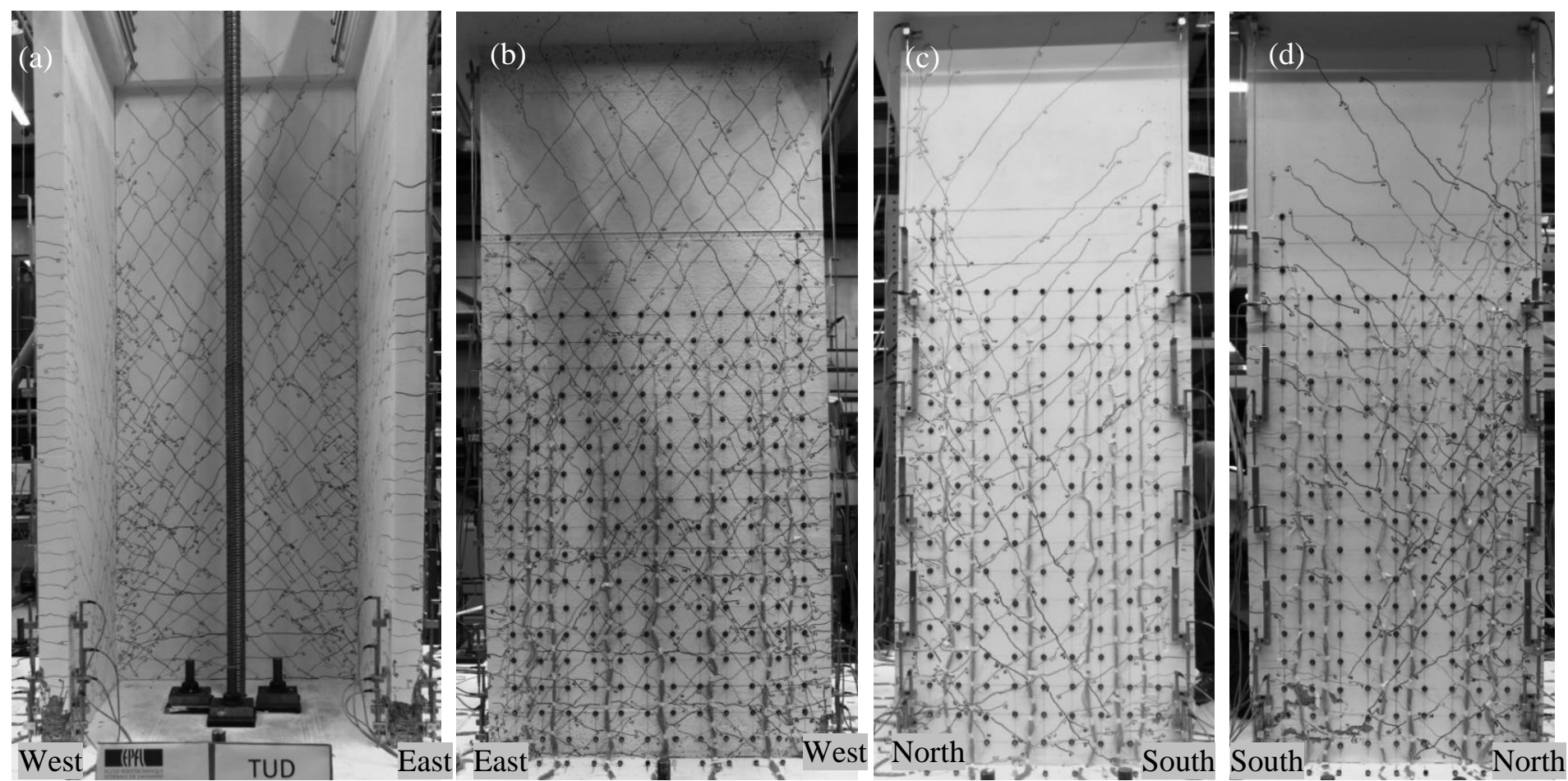

Figure 12 TUD: Crack patterns at the beginning of 1.5\% drift cycles: front view (a); back view (b); view of the West flange (concentrated reinforcement) (c) and view of the East flange (distributed reinforcement) (d) 
Crack angles in the unconfined concrete part of the flanges were measured from photos, averaging the angles over the height $h=0-1.7 \mathrm{~m}$ for cracks that formed for the same loading direction. Crack angles with the wall vertical axis were $\sim 15-25 \%$ smaller for the West flange than for the East one when flange ends were in tension due to $\sim 15 \%$ higher force capacity (and hence also higher shear demand) of the former. Crack angles varied between TUC and TUD, with 30\% smaller angles with the wall vertical axis measured for TUD, indicating the increased shear demand imposed on this wall, both on the web and on the flanges (Figures 11 and 12). In addition the cracks were more closely spaced for TUD, which is probably the result of the more closely spaced shear reinforcement for this test unit.
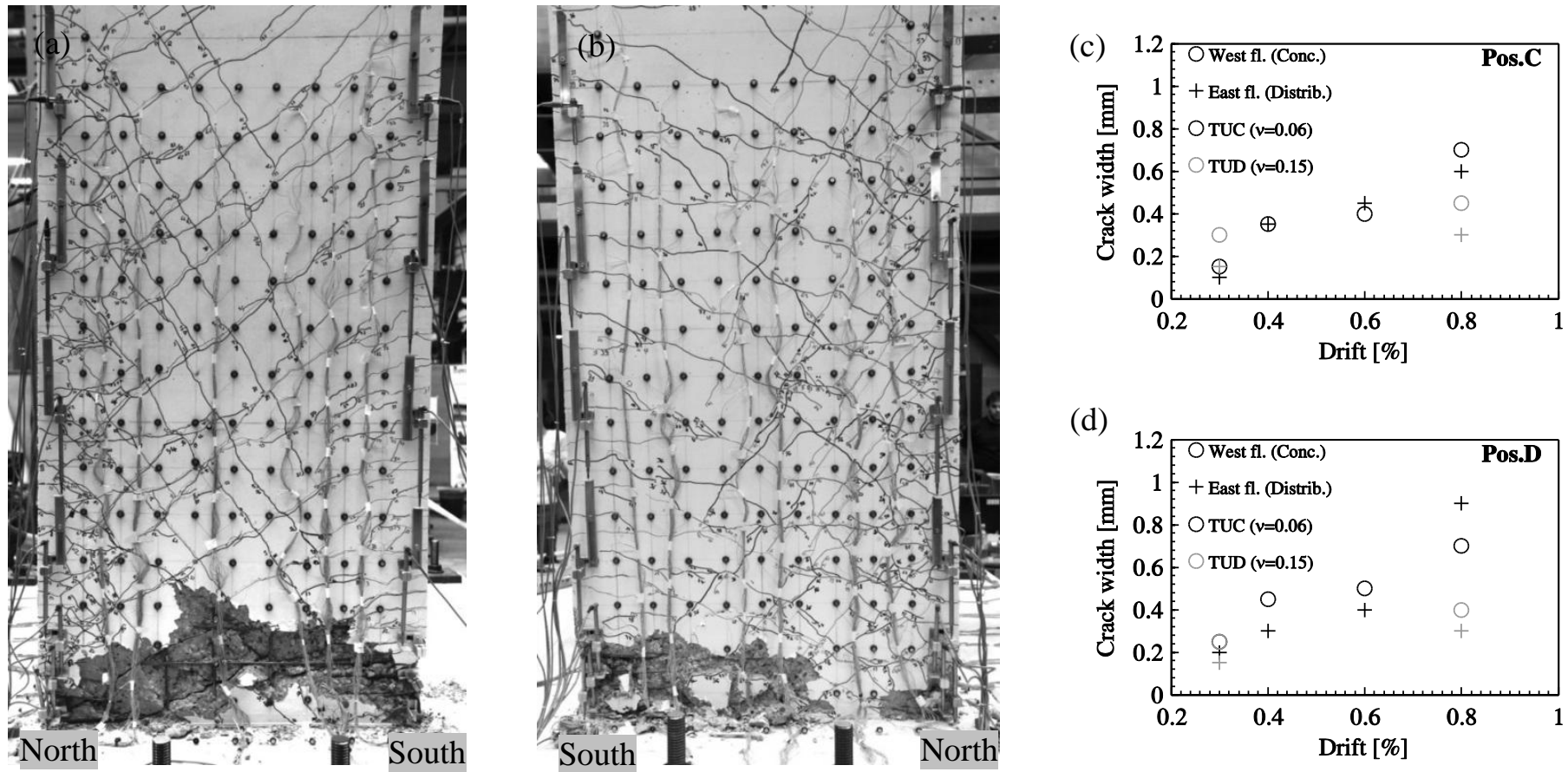

Figure 13 Influence of the vertical reinforcement layout on the damage to the unconfined concrete of the wall flanges. TUC wall flange condition at the end of the test: concentrated reinforcement layout (West flange) (a) and distributed reinforcement layout (East flange) (b). Maximum crack widths in the two flanges under symmetrical loading conditions (c-d)

\subsection{Local deformation response specific to diagonal loading}

This section presents strain profiles that illustrate the deformation response specific to U-shaped walls under diagonal loading. More specifically, the out-of-plane bending of the flanges is discussed in Section 3.3.1 and the section deformation at the wall base in Section 3.3.2. 


\subsubsection{Vertical strains on the inner and outer side of the flange ends}

The vertical strains on the inside and the outside of the flange ends were obtained from measurements of the LVDT chains mounted on the inner and outer sides of the flange ends (Figure $2 b$ and Figure 14b, d). Figure 14 shows these vertical strains obtained for diagonal loading at drifts of $0.4 \%$ and $1.0 \%$. The former corresponds approximately to yield drift while the latter corresponds to the largest drift that was reached by both TUC and TUD in both diagonal loading directions.

The strains shown in Figure 14 are computed for the inner and outer faces of the wall; for this purpose the measurements were corrected for the fact that there was an offset of approximately $4 \mathrm{~cm}$ between wall face and LVDT. The correction was done assuming that the strains varied linearly over the flange thickness, i.e., between the LVDT chains on the inner and the outer side of the flange end.

When the flange ends are under compression (positions $\mathrm{E}$ and $\mathrm{H}$ ), the compressive strains on the outer flange face that were measured with the lowest LVDT $(h=50-150 \mathrm{~mm})$ are up to $\sim 2.5$ times larger than on the inner flange face (Figure 14a-d). When the flange ends undergo tension (positions F and G) the tensile strains on the outside are again larger than on the inside but only by a factor up to $\sim 1.4$ (Figure $14 \mathrm{e}-\mathrm{h}$ ). This strain gradient was observed also for symmetric loading positions (NS direction) but was significantly larger in the case of diagonal loading. The large strain gradient under diagonal loading diagonal loading promotes the out-of-plane buckling of the flange ends (Section 3.1.1). As discussed in Section 3.1, TUC failed after out-of-plane buckling of the West flange end. For TUD, the out-of-plane buckling was not critical since due to the increased axial load ratio the tensile strains at the flange ends, which are crucial for the triggering out-of-plane buckling ([14][15]), were approximately $60 \%$ smaller than for TUC.

\subsubsection{Vertical strains at the base of the wall}

The vertical strains at the base of the wall, which are discussed in this section, were derived from the optical measurement data and were therefore taken on the outer perimeter of the walls. The first two rows of LEDs, namely the row on the foundation and the first row on the wall, were used to determine average vertical strains for $h=0-75 \mathrm{~mm}$. Figure 15 shows these vertical strain profiles at the wall base along the perimeter of the U-shaped section for the diagonal loading directions again plotted for the two above mentioned drift levels, i.e., $0.4 \%$ and $1.0 \%$. 

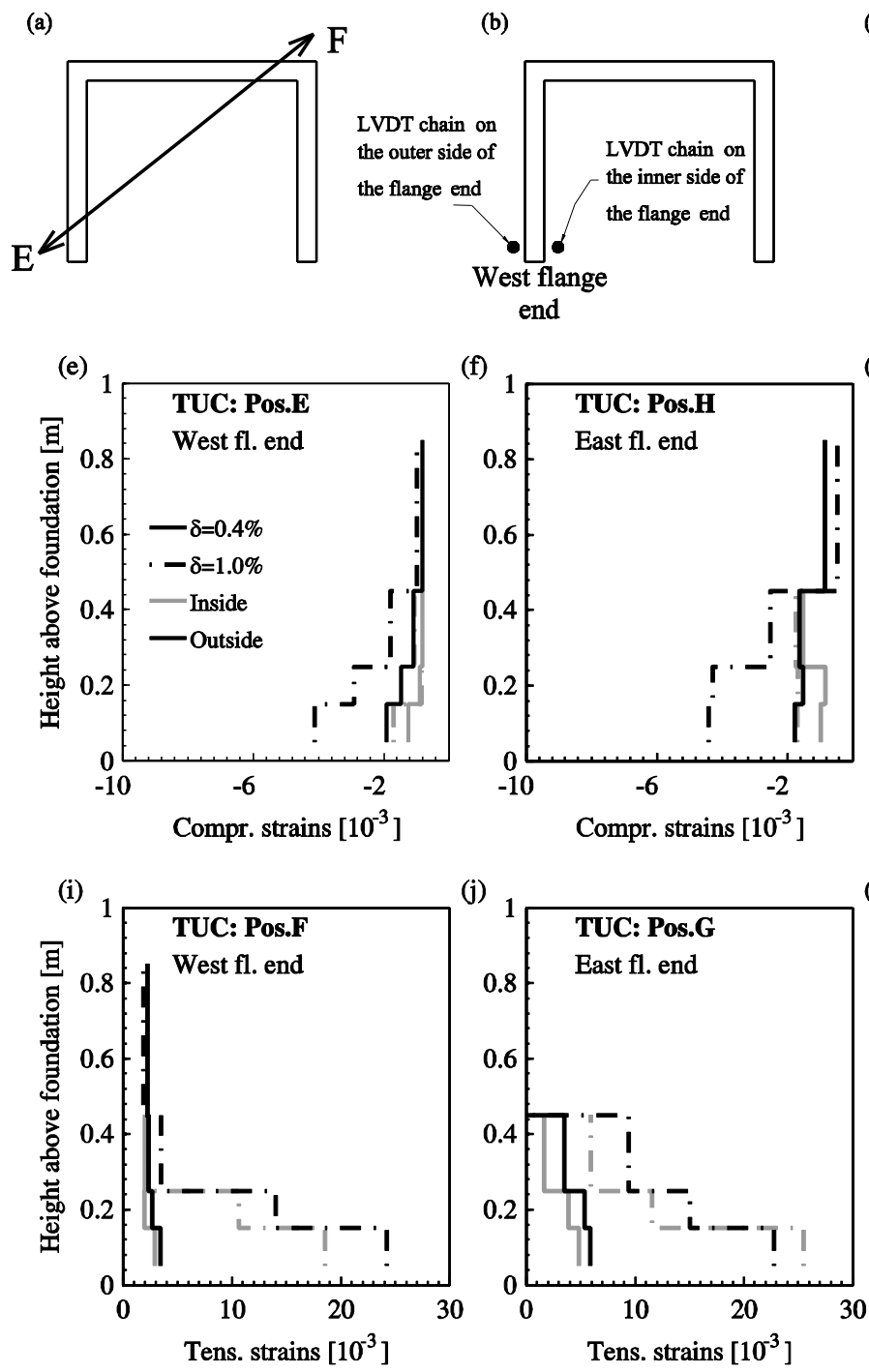

(c)

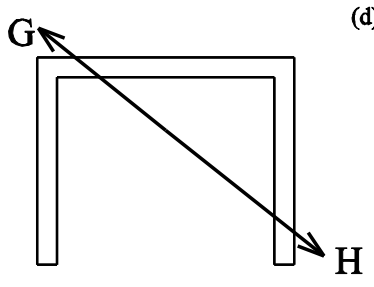

(d)

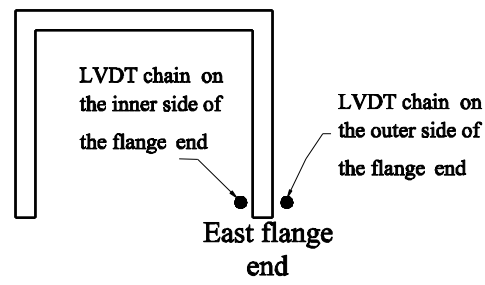

(h)
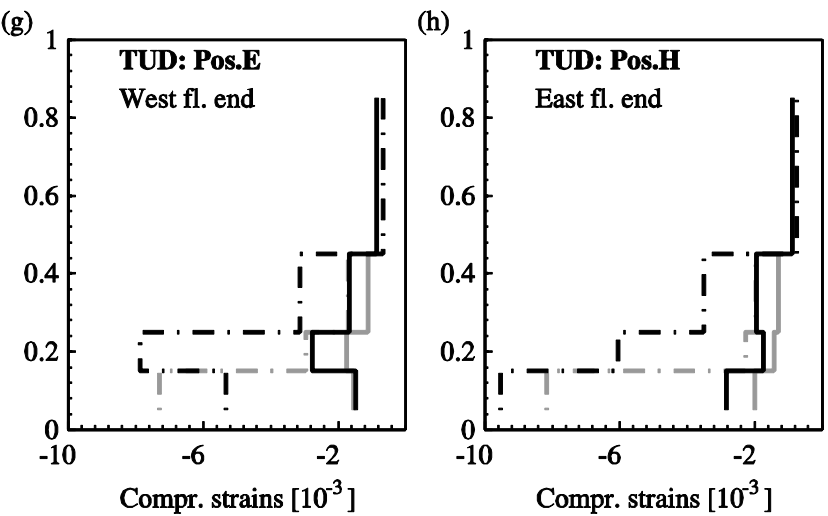
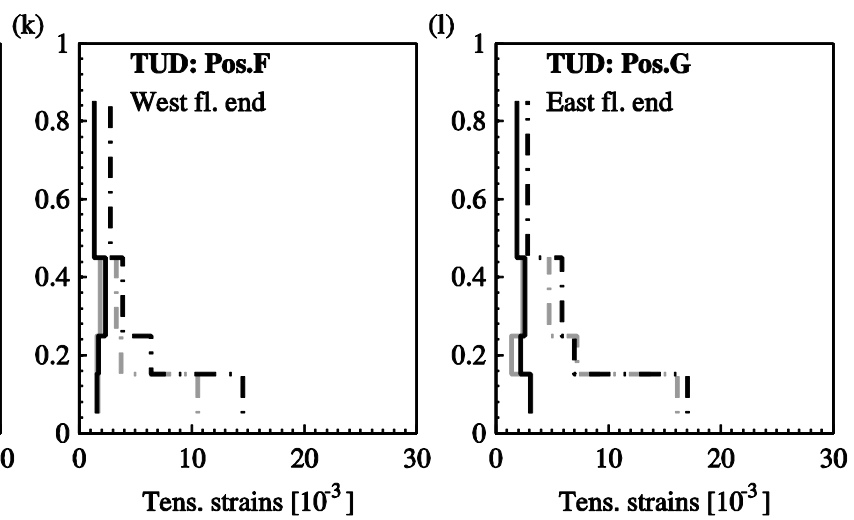

Figure 14 TUC and TUD: Vertical strains on the inside and outside of the flange ends (e-1) computed from measurements of LVDT chains mounted on the two sides of the flange ends (a-d)

This height interval, $h=0-75 \mathrm{~mm}$, at the base of the wall represents the relevant section for the force transfer mechanism from wall to foundation. While the magnitudes of the strains over $h=0-75 \mathrm{~mm}$ may be influenced by the tensile and compressive strain penetration into the foundation, the general trends in the strain distribution along the wall perimeter (i.e. whether strains are compressive or tensile) are not affected. Therefore it is possible to compare qualitatively the experimentally obtained vertical strain distribution with the one estimated using plane section analysis, a widely used analytical tool which forms the 
basis of most beam-column formulations. The two strain profiles: experimental and analytical are compared later in this section and the discrepancies between the two are discussed.

Figure $15 \mathrm{~b}$ shows the vertical strain distribution at the wall base for loading towards position E of TUC. Peak values of compressive strains were attained - as expected - at the flange end but also near the intersection of web and West flange. This second peak compressive strain indicates the presence of a compression zone at the intersection of web and West flange which is less evident at drift levels in the elastic range ( $0.4 \%$ drift $)$ and more pronounced after reaching the nominal moment capacity $(1.0 \%$ drift). The presence of this compression zone is important because, it cannot be captured by a plane section analysis but might be at the core of the force transfer mechanism from wall to foundation for shear forces in the direction of the web as discussed in the following section.

\section{Comparison with section analysis estimates}

The plane section analysis of the U-shaped wall was performed using a zero-length fibre element in the "Opensees" software [18]. The U-shaped section was divided into 212 concrete fibres and 66 reinforcement fibres. The concrete areas were grouped into different zones depending on the degree of confinement. The Concrete04 material model was used for the stressstrain behaviour of the concrete fibres, while confinement properties were computed according to Mander et al.[19]. The Steel02 material model with default parameters was used for the reinforcement stress-strain behaviour. Monotonic analyses were performed in displacement control (i.e., curvature control) along the geometric diagonals of the section. Yield, nominal and ultimate strain limits were determined following recommendations by Priestley et al. [20].

Figure 16 compares for position E of TUC the experimentally obtained vertical strain distribution at the wall base with the one obtained from section analysis. This figure shows that section analysis fails to capture the parabolic variation of the experimental compressive strains along the West flange, with the two compressive strain peaks at the West flange end and the corner between web and West flange. As a consequence, the compression zone at the intersection of web and West flange where high compressive strains were measured (i.e., almost as high as in the West flange end) is also not captured with the plane section assumption. As previously stated, the presence of the extra compression zone at the corner web-flange plays a role in the force transfer mechanism from wall to foundation. 
Shear forces can be transferred from wall to foundation only through compression zones at the base of the wall as only small shear forces can be transferred through a tension zone. At position E, section analysis yields only one compression zone at the West flange end (Figure 16c). This would imply that all shear forces are transferred to the foundation at the West flange end. The shear force in East-West direction, which is originally carried by the web (Figure 16a), would therefore be transferred as an out-of-plane shear force through the West flange end. The experimental vertical strain profile (Figure 16b) indicates however an additional compression zone at the corner between web and flange which can serve for transferring the web shear force to the foundation through a more direct in-plane force path. While the test setup did not allow measuring the distribution of reaction forces along the base of the wall, the compression zone at the corner between web and West flange represents strong evidence that at least part of the shear force in the web is transferred to the foundation through this compression zone.

Similarly, at position F, the experimentally determined vertical strains deviate again from the plane section analysis estimates (Figure 17b-c) due the presence of a compression zone at the corner between West flange and web (Figure 16c and Figure 17a-b). For this case, it is the shear force from the West flange that is most likely at least partially transferred to the foundation through this corner. Analogous comments apply to positions H and G and to TUD (Figure 16d-i).

Another difference between the experimentally obtained vertical strain distribution at the wall base and the one obtained from section analysis at position $\mathrm{E}$ is the magnitude of the vertical strains at the East flange end (Figure 16). Although as previously stated the magnitudes of the two vertical strain distributions cannot be directly compared, it is however important to note that the magnitude of the experimentally determined strains closest to the East flange end is lower than the reinforcement yield strain even at a drift of $1.0 \%$, i.e., approximately when the nominal moment is reached. The experimentally determined vertical base tensile strains are expected to be influenced by tensile strain penetration into the foundation which increases the values of the tensile base strains [21]. However, the experimentally determined strains are still about four times lower than the section analysis strains at the East flange end (Figure 16c). This clearly indicates that the experimentally determined tensile strains in the East flange end are significantly lower than section analysis predictions, and hence so is the tensile force provided by the reinforcement in this region. Therefore, the contribution of the tension reinforcement in the East flange to the wall strength is significantly lower than what section analysis suggests, i.e., not all 
reinforcement in the East flange is contributing effectively to the wall strength. Analogous comments apply to positions E and $\mathrm{H}$ of TUD. The previous observation on the effective contribution of the tension reinforcement does not affect positions $\mathrm{F}$ and G. For these positions the flange ends are the most tensioned zones of the section and hence the reinforcement in these zones contributes significantly to the wall strength. The implications of this are further discussed in Section 3.5.

Such significant deviations from the plane section assumption are possible due to the large shear deformations of the sections of slender core walls under diagonal loading. Shear deformations can account up to $50 \%$ of the total wall section deformation when sections are mainly in tension ([2] and [6]) and similar values have been found also for the U-shaped walls presented herein (see Section 3.4).

(a)

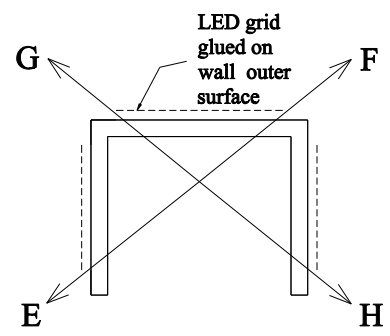

(d) TUC: Pos. H

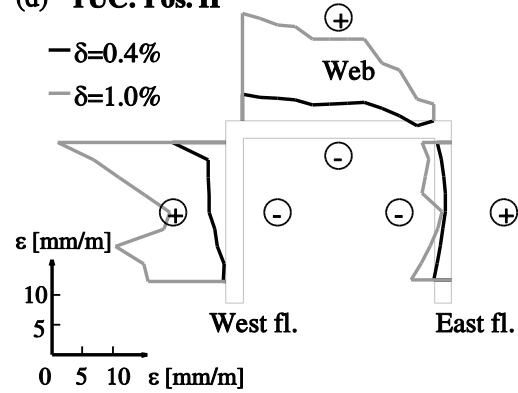

(g) TUD: Pos. F

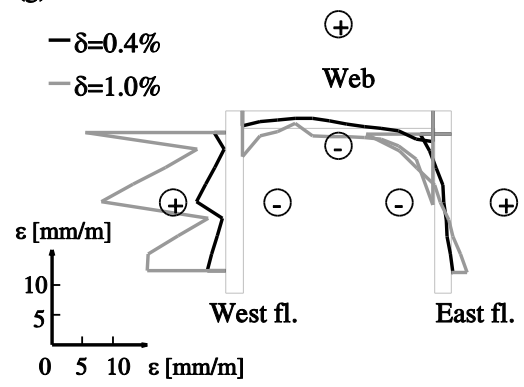

(b) TUC: Pos. E

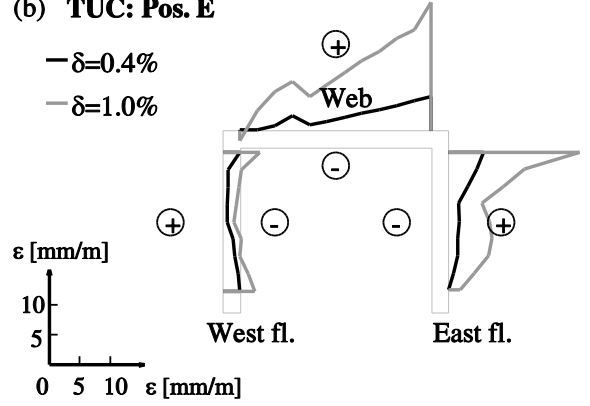

(e) TUC: Pos. G

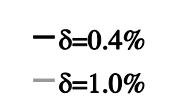

(c) TUC: Pos. F

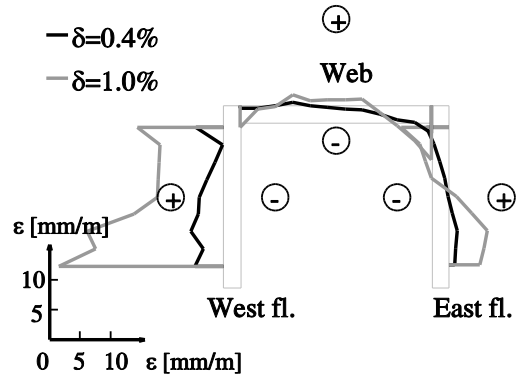

(f) TUD: Pos. E

TUD: Pos.
$-\delta=0.4 \%$

$-\delta=1.0 \%$

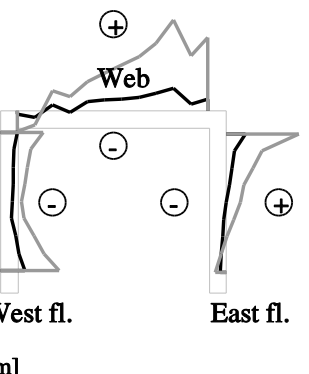

(h) TUD: Pos. H

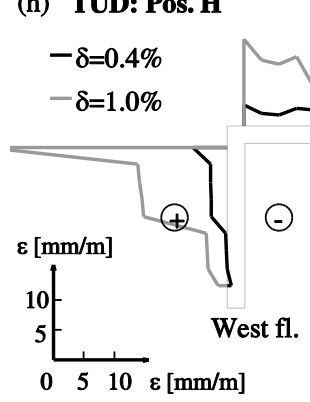

(i) TUD: Pos. G

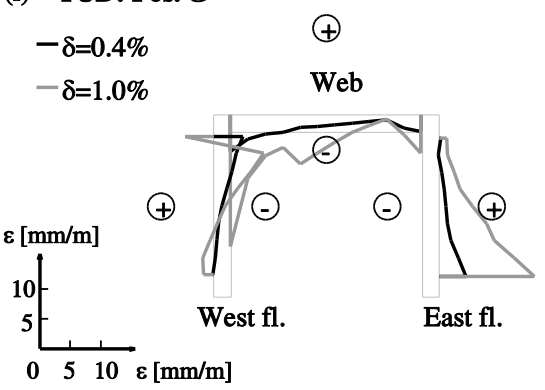

Figure 15 TUC and TUD: Vertical strains at the base of the wall under diagonal loading directions determined from optical measurements over the height $\mathrm{h}=0-75 \mathrm{~mm}$ above foundation on the outer perimeter of the wall. Tensile strains are plotted on the outside of the $\mathrm{U}$-shaped section (positive strains) and compressive strains on the inside (negative strains). The values of the strains can be measured from the outer face of the U-shaped section using the strain scale provided in the left down corner of each subplot. 
(a)

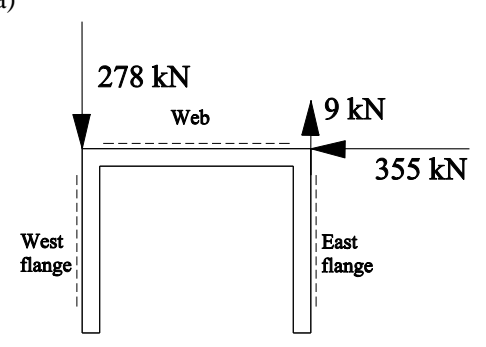

(b) TUC: Pos. E

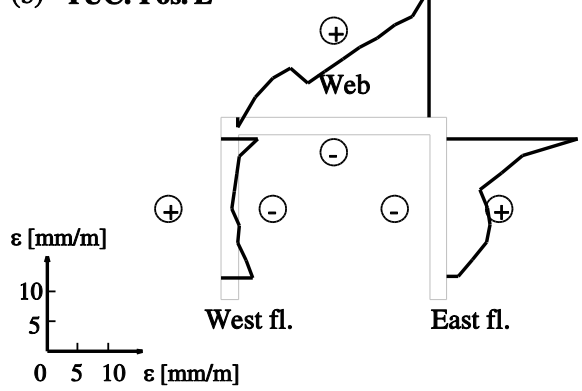

(c) TUC: Pos. E

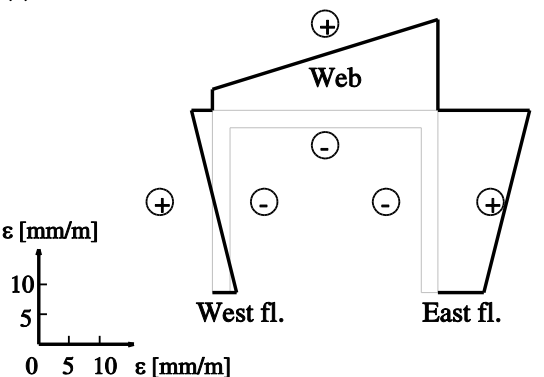

Figure 16 TUC: Compressive zones at the wall base under diagonal loading at position $\mathrm{E}$ at nominal point: nominal forces (a); vertical strain distribution from experimental measurements at the outer side of the wall (b) and from plane section analysis prediction also at the outer side of the wall (c). The values of the strains can be measured from the outer face of the U-shaped section using the strain scale provided in the left down corner of the subplots.

(a)

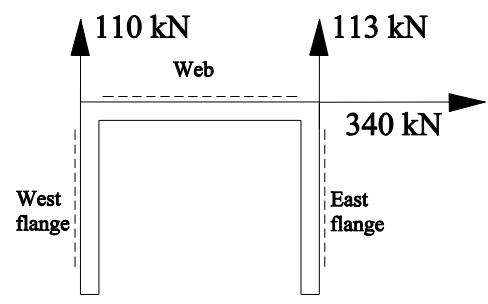

(b) TUC: Pos. F

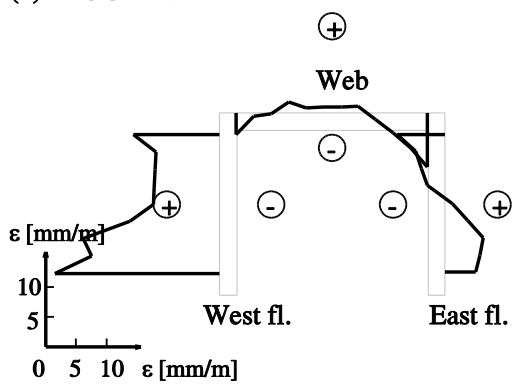

(c) TUC: Pos. F

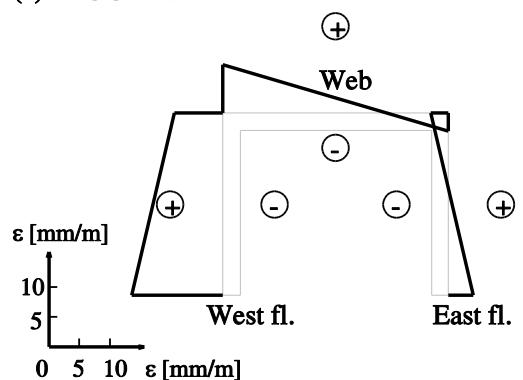

Figure 17 TUC: Compressive zones at the wall base under diagonal loading at position $\mathrm{F}$ at nominal point: nominal forces (a); vertical strain distribution from (b) experimental measurements and from plane section analysis prediction (c). The values of the strains can be measured from the outer face of the U-shaped section using the strain scale provided in the left down corner of the subplots.

\section{Influence on confinement lengths}

An important issue that results from the analysis of vertical strain profiles at the wall base is the size of the compression zone at positions $\mathrm{H}$ shown in Figure 18 but also at position E. At these positions the compression zones are very deep (in particular along the outer perimeter). This large compression zone creates the potential for large compressive strains outside the confined area and hence for concrete crushing outside the confined boundary elements. Figure 18 compares the extent of the compressed flange zone under diagonal loading with the flange end in compression (positions $\mathrm{H}$ or E) against the compressed zone under symmetrical loading with both flange ends in compression (position C). The strain levels are compared for $0.6 \%$ drift which is the largest drift for which the wall was loaded to positions $\mathrm{C}$ and $\mathrm{H}$.

Both experimental data and section analysis results indicate that the compression zone is significantly larger at position $\mathrm{H}$ (and by extension also at E) than at $\mathrm{C}$. Hence the diagonal loading case with the flange ends in compression should be the determining one for computing the confinement length of the flanges. 
(a)

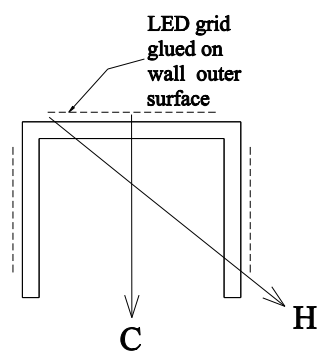

(b)

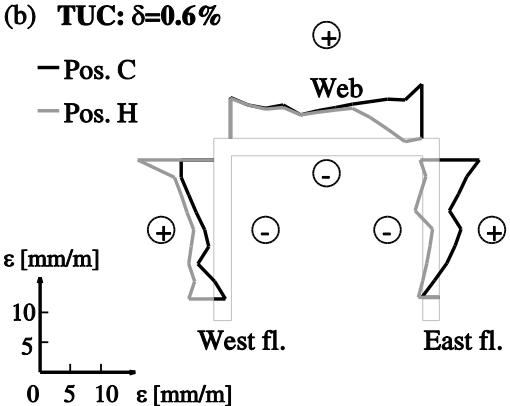

(c) TUC: $\delta=$ nominal

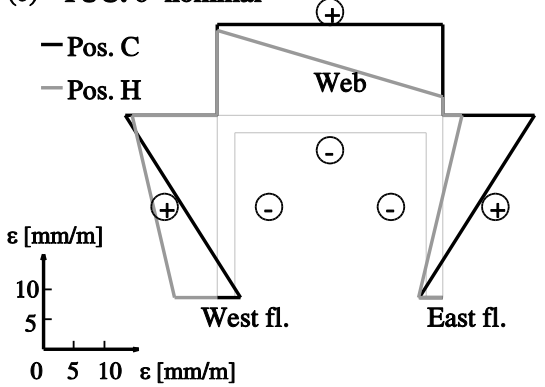

Figure 18 TUC: Vertical strains at the base of the wall for loading with the both flange ends in compression (position C) and with one flange end in compression (position $\mathrm{H}$ ): loading positions (a), experimentally determined on the outer wall (b) and section analysis (c). Tensile strains are marked as positive and compressive strains negative. The values of the strains can be measured from the outer face of the U-shaped section using the strain scale provided in the left down corner of the subplots.

\subsection{Shear to flexural displacements ratios}

Typically the total horizontal displacement of a $\mathrm{RC}$ wall is considered to be composed of: flexural deformations (including base rotation due to strain penetration into foundation), shear deformations and sliding displacements at the wall base. In order to investigate the contribution of the shear displacements to the total displacement, the shear to flexural displacements ratio $\left(\Delta_{s} / \Delta_{f}\right)$ is generally used as an indicator. This ratio was found to be constant over the inelastic range for flexurecontrolled walls ([2], [6], [22] and [24]).

For the two tests presented in this paper, the $\Delta_{s} / \Delta_{f}$ ratios were determined from the optical measurement data. For each wall section component, the LED grid was divided into rectangular elements each spanning horizontally between the two outer LED columns and vertically between two consecutive LED rows. For each such rectangular element, flexural deformations were computed by double-integration of the curvatures and shear deformations were computed from the change in length of the diagonals of the elements, according to the procedure explained in more detail in Hannewald [23]. The procedure for computing the curvatures was slightly modified by assuming a best linear fit of the vertical displacements over each row of LEDs. Flexural deformations at the height of load application were derived assuming that curvatures decrease linearly to zero from the top of the measurement grid $(\sim 1.7 \mathrm{~m})$ to the height of load application $\left(h_{E W}=3.35 \mathrm{~m}\right.$ and $\left.h_{N S}=2.95 \mathrm{~m}\right)$. Over this same height interval shear deformations were considered to be zero, as such deformations concentrate mainly in the plastic hinge region ([21] and [24]) and hence below the height of $\sim 1.7 \mathrm{~m}$. 
The sliding displacements at the wall base were determined as the difference in horizontal displacements of the foundation row of LEDs and the first row on the wall (measuring height $h=0-75 \mathrm{~mm}$ ). In agreement with findings in [2], sliding displacements were small accounting for a maximum of 3.7\%,5\% and 3.5\% of the total top displacement for the web, West flange and East flange respectively for TUC at $2.5 \%$ drift and accounted for less than $2 \%$ for all wall sections of TUD. Therefore the sliding displacements were included in the computation of the shear displacements.

Previous experimental research on RC core walls ([2] and [6]) found that the contribution of shear displacements to the total displacements depends strongly on the loading direction, with the largest contribution being when wall sections (flanges or web) are under net tension. For U-shaped walls, this is the case for the web at positions $\mathrm{E}$ and $\mathrm{H}$, the West flange at position $\mathrm{F}$ and the East flange at position G. The shear displacements for these loading cases were found to be significantly larger than those for typical slender rectangular walls ([2] and [6]). These trends are confirmed also by the two wall tests presented herein (Figure 19b, c and Table 4). The shear deformations are as large as $\sim 50-70 \%$ of the flexural deformations for the web at positions $\mathrm{E}$ and $\mathrm{H}$ (Figure 19c - left), and as large as $\sim 60-100 \%$ of the flexural deformations for the flange under tension at diagonal loading: positions $\mathrm{F}$ and $\mathrm{G}$ (Figure $19 \mathrm{~b}$ - right). For both the flanges and the web mainly in tension at these loading positions, the contribution of the shear deformations to the total deformation increased with higher axial load ratio (Figure 19b-c). Higher axial load ratio leads to higher shear demand on the wall sections, hence smaller crack angles with vertical axis of the wall (Section 3.2) and therefore larger shear deformations ([21], [23] and [24]).

The vertical reinforcement layout (concentrated or distributed) also influences the contribution of the shear displacements to the total displacements: $\Delta_{s} / \Delta_{f}$ ratios are larger for the flange with concentrated reinforcement layout than for the flange with distributed reinforcement layout case ([3] and [17]). Also this trend is confirmed by results from TUC and TUD, by comparing the two flanges with concentrated (West) and distributed (East) vertical reinforcement distribution under symmetric loading conditions. More precisely $\Delta_{s} / \Delta_{f}$ ratios are compared for the NS cycles - positions C and D (Figure 19d) and for the diagonal cycles - West flange at positions E and F with East flange at positions H and G (Figure $19 \mathrm{~b}$ ). $\Delta_{s} / \Delta_{f}$ ratios are averaged over the drift range over which the $\Delta_{s} / \Delta_{f}$ ratios are approximately constant, i.e., $0.6 \%$ to $2.0 \%$ drift or $1.0 \%$ $2.0 \%$ drift (flange in tension at positions F and G) (Figure 19), are given in Table 4. 
The flange with concentrated reinforcement layout (West flange) leads to larger $\Delta_{s} / \Delta_{f}$ ratios than the flange with distributed reinforcement layout (East flange). The difference in $\Delta_{s} \Delta_{f}$ ratios results from the different longitudinal reinforcement ratios of the wall section between the boundary elements, which is smaller for the concentrated reinforcement layout. As a result, crack widths are larger in this area (Section 3.2) and so are shear deformations. This holds for either test units irrespective of whether the flange is mainly under tension (positions F, G and D) or compression (positions C, E and H). While the difference in percentages is substantial $(\sim 14 \%$ to $\sim 44 \%)$, the absolute difference in $\Delta_{s} / \Delta_{f}$ ratios between the two flanges is only significant when the flanges are in tension and the wall is loaded in the diagonal direction (difference in $\Delta_{s} / \Delta_{f}$ ratios of 0.20 and 0.29 ) and relatively small when the flanges are in compression, i.e., as small as 0.06 (Table 4).
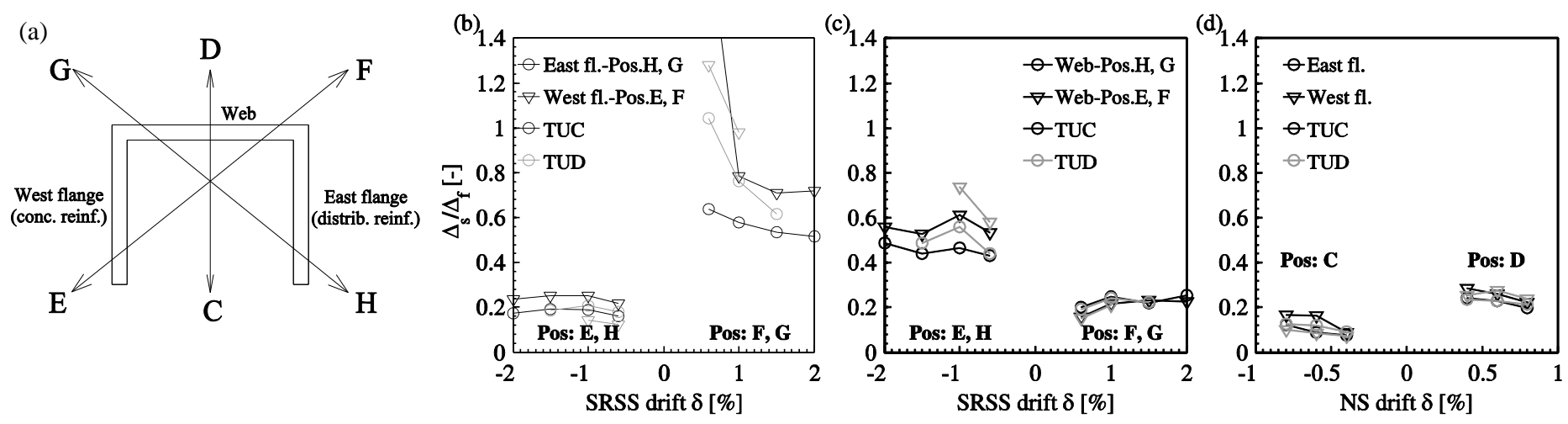

Figure 19 TUC and TUD: shear to flexural displacement ratios for: the flange under compression at position $\mathrm{E}$ and $\mathrm{H}$ (a), web under compression at positions $\mathrm{F}$ and $\mathrm{G}$ and under tension at $\mathrm{E}$ and $\mathrm{H}(\mathrm{b})$ and both flanges at positions $\mathrm{C}$ and $\mathrm{D}$ (c)

Table 4 Average shear to flexural deformation ratios: comparison between symmetric loading positions for the two flanges with concentrated and distributed reinforcement

\begin{tabular}{llcccc}
\hline \multicolumn{4}{c}{ Average $\Delta_{s} / \Delta_{f}$} \\
\hline & \multicolumn{3}{c}{$\begin{array}{c}\text { Flange partially or } \\
\text { mainly in } \\
\text { compression }\end{array}$} & \multicolumn{2}{c}{$\begin{array}{c}\text { Flange mainly in } \\
\text { tension }\end{array}$} \\
\hline \multirow{2}{*}{ Flange } & $\begin{array}{c}\text { Pos. } \\
\text { TUC }\end{array}$ & E/H & Pos. C & Pos. F/G & Pos. D \\
\hline \multirow{2}{*}{ Distrib. (East) } & 0.18 & 0.10 & 0.54 & 0.21 \\
& Conc. (West) & 0.24 & 0.14 & 0.74 & 0.24 \\
& Difference distr.-conc. & 0.06 & 0.04 & 0.20 & 0.03 \\
& Percentage difference (\%) & $33 \%$ & $40 \%$ & $37 \%$ & $14 \%$ \\
\hline \multirow{2}{*}{ TUD } & Distrib. (East) & 0.19 & 0.11 & 0.69 & 0.22 \\
& Conc. (West) & 0.13 & 0.09 & 0.98 & 0.26 \\
& Difference distr.-conc. & -0.06 & -0.02 & 0.29 & 0.04 \\
& Percentage difference (\%) & $-32 \%$ & $-18 \%$ & $42 \%$ & $18 \%$ \\
\hline
\end{tabular}


This does, however, not apply to TUD when the flanges are in compression: here the $\Delta_{s} / \Delta_{f}$ ratios are slightly larger for the flange with distributed reinforcement (East flange) than for the flange with concentrated reinforcement (West flange). It is postulated that this small difference stems from the assumptions behind the derivation of the flexural displacements: the flexural displacements were computed fitting a linear strain profile over the flange length, which yields for the concentrated reinforcement layout under high axial forces a poorer fit than for the other cases. As a result, the flexural displacements as well as the total displacements tend to be overestimated (Figure 20).
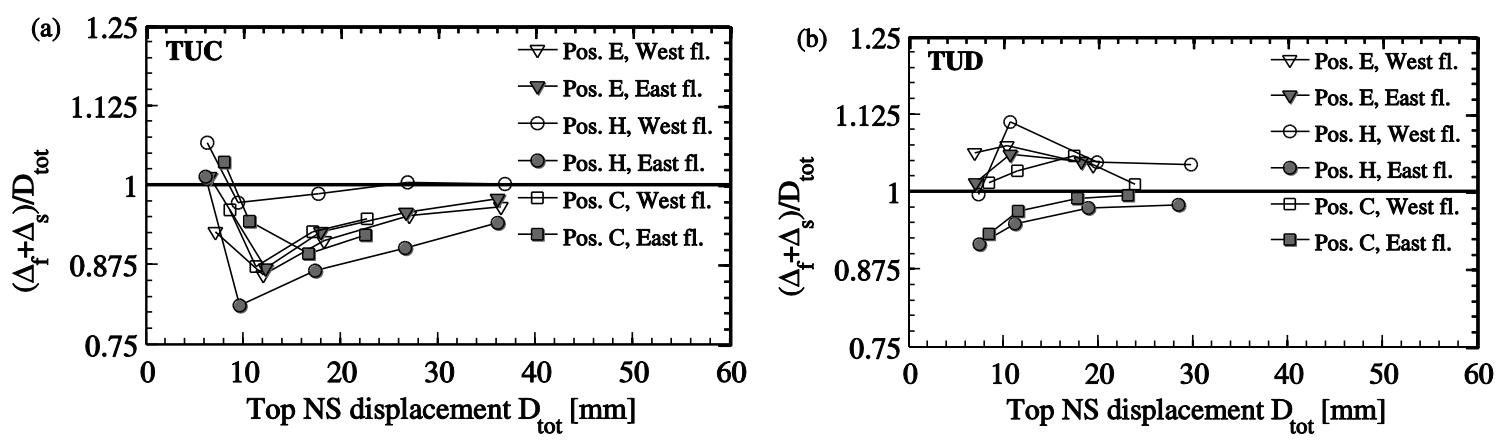

Figure 20 TUC and TUD: comparison of the top displacement obtained as the sum of flexural and shear displacements, derived from the LED measurements, with the top displacements $D_{\text {tot }}$ as measured by the top LVDTs and corrected for foundation flexibility. Comparison is done for the two wall flanges, West and East at positions $\mathrm{E}, \mathrm{H}$ and $\mathrm{C}$.

\subsection{Comparison of experimentally determined moment capacities with section analysis estimates}

The U-shaped wall strength capacity under diagonal loading was shown to be significantly overestimated by a plane section analysis, especially for loading with one flange end in compression (positions E and H) [2]. For the two U-shaped wall tests presented here, the experimentally determined moment-curvature hystereses are compared with the values obtained from section analysis (Figure 21). The numerical model used for the section analysis was briefly described in Section 3.3.2. The experimental curvature was determined from the LVDT measurements, corrected to filter-out the influence of tensile and compressive strain penetration. For this, the procedure used by Hines et al. [21] was employed. The best linear fit line of the curvature profile over the height interval $\mathrm{h}=50-850 \mathrm{~mm}$ was extrapolated to the wall base and the intersecting value was taken as the experimental base curvature (Figure 20d). The SRSS moment was computed as:

$$
M_{S R S S}=\sqrt{M_{E W}^{2}+M_{N S}^{2}} * \operatorname{sign}\left(\Delta_{N S}\right)
$$


where $M_{E W}$ and $M_{N S}$ are the moments at the base of the wall for bending around the axis perpendicular to the web and parallel to the web respectively. The SRSS value was multiplied by the sign of the NS displacement for plotting the hysteresis loops consistently.

For both test units, section analysis overestimates the SRSS moment at positions $\mathrm{E}$ and $\mathrm{H}$ by $\sim 15$ to $25 \%$ by. For position F of TUC and G of both TUC and TUD the match is relatively good (less than $10 \%$ overestimation) (Figure 21 b-c, e-f). For position F of TUD the overestimation is slightly higher $(\sim 12 \%)$ but this is because the maximum moment capacity was most likely not reached for this position due to prior wall failure in the other diagonal direction (see Section 3.1.2 and compare Figure 21e and f). The SRSS moment capacity is overestimated by section analysis because it fails to capture the experimentally determined vertical strain distribution at the base of the wall under diagonal loading (see discussion in Section 3.3.2).

(a)

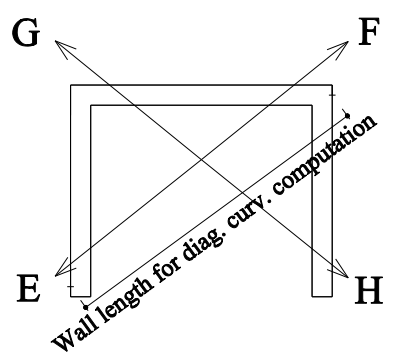

(d)

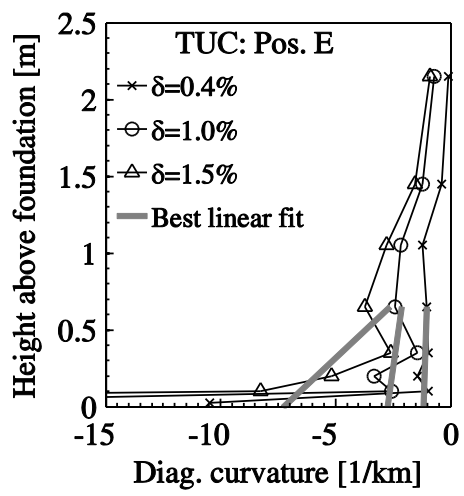

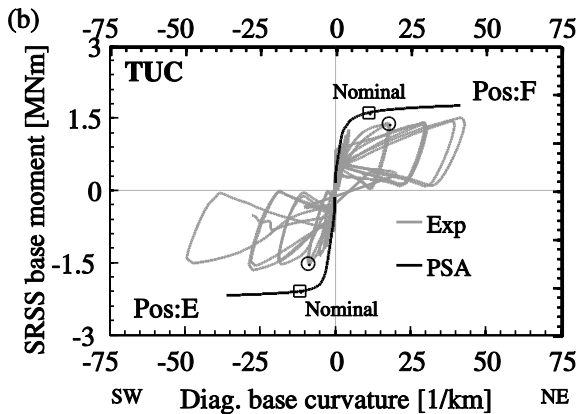
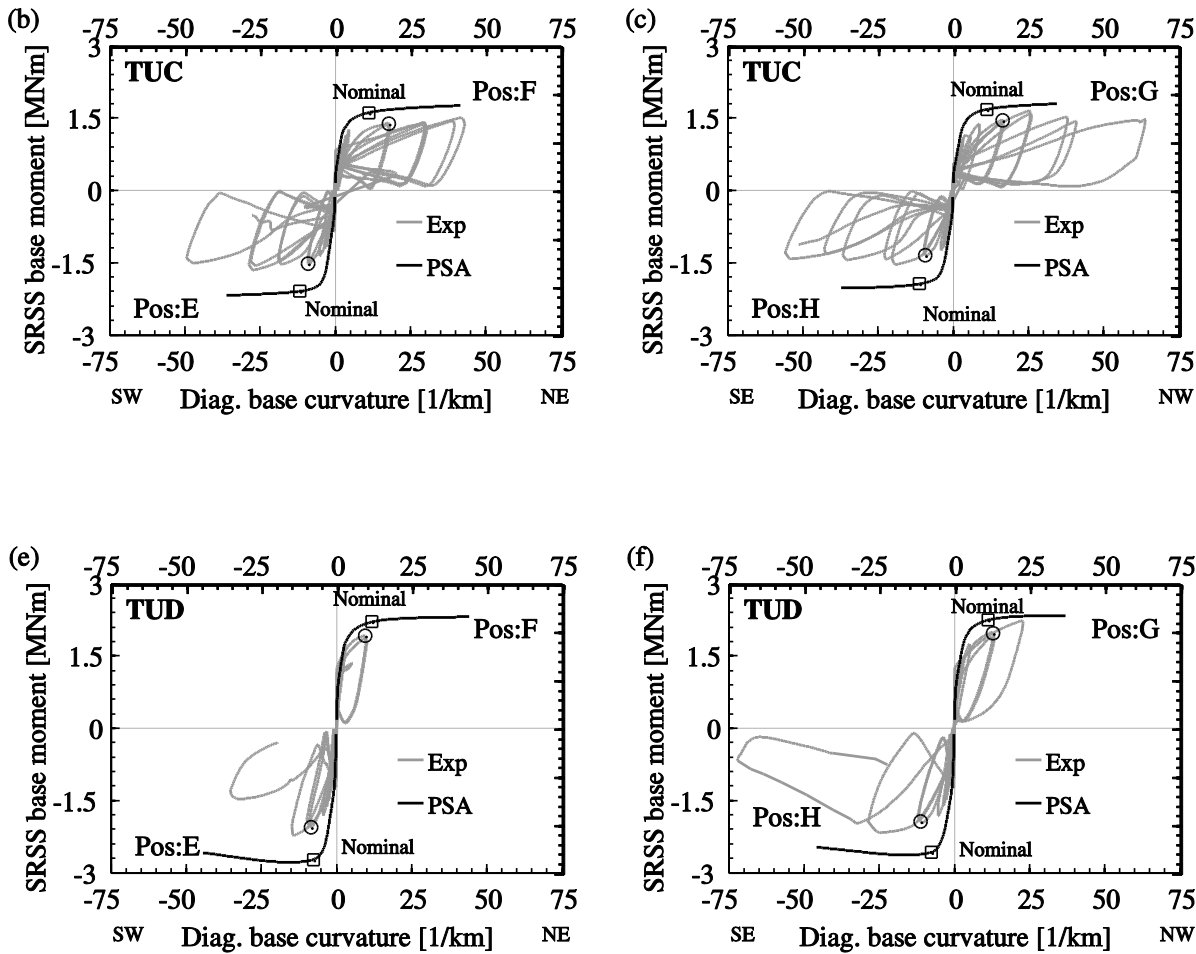

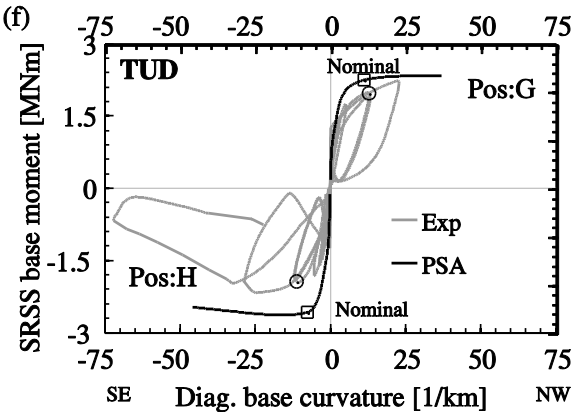

Figure 21 Comparison between the experimentally determined moment-curvatures and results from plane section analysis (PSA) for the diagonal loading directions (a) for TUC (b-d) and TUD (e-i). The position of the nominal point is indicated in the moment-curvature relationships for both experiemental (round marker) and plane section analysis (square marker). 
More specifically, plane section analysis overestimates the flange width over which the tension reinforcement contributes effectively to the strength capacity of the wall and hence overestimates also the wall moment capacity. This is effect was found to be important at positions $\mathrm{E}$ and $\mathrm{H}$ (see Section 3.3.2) and hence explains the larger moment overestimations at these loading positions. In addition, plane section analysis does not capture the extra compression zone at the corner web-flange (see Section 3.3.2). Wall moment capacity estimated with plane section analysis accounts for this zone as being in tension and hence the reinforcement in this corner contributes to the wall strength which should not be the case as these zones are in compression (Figure 16 and Figure 17). This compression zone is again more evident at positions E and $\mathrm{H}$ (Figure 15b, d, f, h) and less important for position F and G (Figure $15 \mathrm{c}, \mathrm{e}, \mathrm{g}$, i) hence also the relatively smaller moment overestimations for the latter loading positions.

\section{Conclusions and outlook}

This article presented results from the experimental tests of two U-shaped walls under quasi-static loading along the diagonal directions of the section, which were loaded up to axial load failure. The main objective was to investigate the specific behaviour of U-shaped walls under diagonal loading. In addition, the effect of distributing the vertical reinforcement along the wall length instead of concentrating it in the boundary elements was studied. From the experimental measurements and observations the following conclusions concerning the behaviour of U-shaped walls under diagonal loading were drawn:

- The plane section assumption, which is the basis of simple analysis tools for RC walls, does not hold for the Ushaped walls under diagonal loading since it fails to capture the presence of additional compression zones at the corners between web and flange. Moreover plane section analysis overestimates the width of the flange over which the tension reinforcement contributes to the wall moment capacity. Both these effects result in overestimations of the moment capacity of U-shaped walls with plane section analysis for diagonal loading with largest overestimations for loading with the flange end in compression. The presence of the compression zones at corners between web and flange could explain the force transfer mechanism from wall to foundation for in-plane shear forces in the web or in the flanges and hence their role in the strength estimation of U-shaped walls under diagonal loading should be further investigated. 
- Flanges of U-shaped wall subjected to bidirectional loading seem prone to out-of-plane buckling. For rectangular walls loaded in-plane, the out-of-plane instability is mainly caused by construction imperfections. For flanges of Ushaped walls, out-of-plane buckling of the flange ends is in addition promoted by the significant vertical strain gradient across the flange width when the wall is subjected to diagonal loading, which leads to an eccentricity of the axial force acting on the boundary element.

- The compression depth of the flange ends is the largest under diagonal loading with one flange end in compression, and hence the confinement length of the flange end should be estimated from this loading case. Particular attention should be given to adapt the confinement reinforcement to the vertical reinforcement layout used, as distributed reinforcement layout will generally require smaller stirrup spacing due to the smaller vertical bar diameter and longer confinement lengths.

- The axial load ratio, which was the main varying parameter between the two tests, was found to influence the wall ultimate displacement and the failure mode. The higher axial load ratio reduced the ultimate displacement capacity of the wall as the failure modes of both test units were compression-controlled. Both walls failed under diagonal loading with one flange end in compression, and their failure modes involved concrete crushing in the flange unconfined part. All these observations underline: (1) the importance of proper confinement of the flange ends to ensure the wall displacement ductility as well as (2) the importance of distributing more than the minimum required vertical reinforcement content within the unconfined concrete part of the wall to delay or avoid excessive concrete crushing in these regions.

The experiments showed that the longitudinal reinforcement layout influenced the following mechanisms:

- Bar buckling: For distributed reinforcement layouts, the diameter of the longitudinal bars in the boundary elements is typically smaller than for concentrated reinforcement layouts. For the same stirrup spacing, bars in the distributed reinforcement layout will therefore buckle and fracture at smaller drifts.

- Out-of-plane buckling of the boundary element over the height of the plastic zone: Mechanical models have shown that the larger the longitudinal reinforcement content of the boundary element, the more prone it is to buckling. This was confirmed by the failure mode of TUC, where only the flange with the concentrated reinforcement developed an 
out-of-plane failure. Hence, one possible way of minimising the potential for out-of-plane buckling of the flange ends is to distribute the vertical reinforcement along the wall length.

- Compression zone depth: Distributed reinforcement layouts lead to larger compression zone depths, which increases the susceptibility to concrete crushing. This was observed for TUD, where the compression depth extended into the non-confined part and a sudden crushing of the entire flange with distributed reinforcement was observed.

- Crack widths: A distributed reinforcement layout features higher reinforcement contents in the wall section between the boundary elements than a concentrated reinforcement layout. The experiments showed that the increased reinforcement content helps controlling the crack widths in this area.

- Shear deformations: As a result of the smaller crack widths, distributing the longitudinal reinforcement reduced also the shear deformations. This seems particularly important for U-shaped walls as shear deformations can account for up $\sim 40-50 \%$ of the total deformation when the flanges or the web are mainly in tension.

The experimental data gathered from the two tests will complement the limited database of core walls subjected to bidirectional loading and will be made soon publicly available accompanied by a data paper. This data will serve as validation for future numerical and mechanical models. Ongoing studies concentrate on developing simple analysis tools for predicting the strength and displacement capacity of U-shaped walls with various geometries for the different loading directions.

\section{Acknowledgements}

Financial support for the tests and for the first author provided by the Swiss National Science Foundation is gratefully acknowledged. The authors would also like to thank the staff of the laboratory of the Institute of Civil Engineering (IIC) at EPFL, in Lausanne, Switzerland, where the tests have been performed, especially to S. Demierre, G. Guignet, A. Krkic, and G. Rouge. Dr. J. Almeida contributed to the paper by providing useful and constructive comments. 


\section{References}

[1] Ile N, Reynouard JM. Behaviour of U-shaped walls subjected to uniaxial and biaxial cyclic lateral loading. Journal of Earthquake Engineering 2005; 9(1):67-94.

[2] Beyer K, Dazio A, Priestley MJN. Quasi-static cyclic tests of two U-shaped reinforced concrete walls. Journal of Earthquake Engineering 2008; 12:1023-1053.

[3] Brueggen BL. Performance of T-shaped reinforced concrete structural walls under multi-directional loading. PhD Thesis. Minneapolis, (US): University of Minnesota; 2008, 499pp.

[4] Kono S, Sakamoto K, Sakashita M. Simulation of seismic load resistance of core-walls for tall buildings. Applied Mechanics and Materials 2011; 82:386-391.

[5] Lowes L, Lehman D, Kuchma D, Mock A, Behrouzi A. Large scale tests of C-shaped reinforced concrete walls. Summary report from NEES project warehouse; https://nees.org/warehouse/project/104, 2013.

[6] Zhang ZW, Li B. Evaluation of seismic performance of slender L-shaped and T-shaped RC structural walls. In: Proceedings of the 2nd European Conference on Earthquake Engineering and Seismology. Paper no. 213; 2014.

[7] SN. SIA262/1: Concrete structures - supplementary specifications. Building Code, Swiss Society of Engineers and Architects (SIA). Zürich (Switzerland); 2003.

[8] Chen WF, Yuan RL. Tensile Strength of Concrete: Double-Punch Test. Journal of the Structural Division, ASCE, August 1980; 106:1673-1693.

[9] CEN. Eurocode 8: Design provisions for earthquake resistance of structures, Part 1: General rules, seismic actions and rules for buildings. EN 1998-1:2004. Brussels (Belgium): European Committee for Standardisation; 2004.

[10] NDI. Optotrak Certus HD, Northern Digital Inc. Waterloo, Ontario (Canada); http://www.ndigital.com/industrial/certushd.php; 2009.

[11] Paulay T, Goodsir WJ. The ductility of structural walls. Bulletin of the New Zealand National Society for Earthquake Engineering 1985; 18(3):250-269.

[12] Rosso A, Almeida JP, Beyer K. Stability of thin reinforced concrete walls under cyclic loads: State-of-the-art and new experimental findings. Bulletin of Earthquake Engineering, under review; 2015. 
[13] Hube MA, Marihuén A, de la Llera JC, Stojadinovic B. Seismic behaviour of slender reinforced concrete walls. Engineering Structures 2014; 80:377-388.

[14] Paulay T, Priestley MJN. Stability of ductile structural walls. ACI Structural Journal 1993, 90(4):385-392.

[15] Chai YH, Elayer DT. Lateral stability of reinforced concrete columns under axial reversed cyclic tension and compression. ACI Structural Journal 1999, 96(5):780-790.

[16] Rosso A, Almeida JP, Constantin R, Beyer K, Sritharan S. Influence of longitudinal reinforcement layouts on RC wall performance. In: Proceedings of the 2nd European Conference on Earthquake Engineering and Seismology. Paper no. 980; 2014.

[17] Sritharan S, Beyer K, Henry RS, Chai YH, Kowalsky M, Bull D. Understanding Poor Seismic Performance of Concrete Walls and Design Implications. Earthquake Spectra 2014, 30(1):307-334.

[18] Mazzoni S, McKenna F, Fenves GL. Opensees Comand Language Manual, Opensees v.2.0, University of California, Berkeley, May 2009.

[19] Mander JB, Priestley MJN, Park R. Theoretical stress-strain model for confined concrete. ASCE Journal of Structural Engineering 1988, 114(8):1804:1826.

[20] Priestley MJN, Calvi GM, Kowalsky MJ. Displacement-based seismic design of structures. Pavia (Italy): IUSS Press; 2007.

[21] Hines E, Restrepo J, Seible F. Force-displacement characterization of well-confined bridge piers. ACI Structural Journal 2004; 101(4):537-548.

[22] Dazio A, Beyer K, Bachmann H. Quasi-static cyclic tests and plastic hinge analysis of RC structural walls. Engineering Structures 2009; 31:1556-1571.

[23] Hannewald P. Seismic behaviour of poorly detailed RC bridge piers. PhD Thesis, Thèse 5894. Lausanne (Switzerland): Ecole Polytéchnique Fédérale de Lausanne; 2013, 166pp.

[24] Beyer K, Dazio A, Priestley MJN. Shear deformations of slender reinforced concrete walls under seismic loading. ACI Structural Journal, March-April 2011; 108(2):167-177. 